\title{
Kidney Cadmium Toxicity, Diabetes and High Blood Pressure: The Perfect Storm
}

\author{
Soisungwan Satarug, ${ }^{1}$ David A. Vesey ${ }^{1}$ and Glenda C. Gobe ${ }^{1}$ \\ ${ }^{1}$ Centre for Kidney Disease Research, Translational Research Institute and The University of Queensland \\ Diamantina Institute, Woolloongabba, Brisbane, Queensland, Australia
}

\begin{abstract}
Cadmium (Cd) is an environmental toxicant of widespread exposure and pervasive toxicity. Absorption, systemic transport and uptake of $\mathrm{Cd}$ are mediated by metal transporters that the body uses for acquisition of physiologically-essential elements, notably of iron, zinc and calcium. Currently, human exposure to Cd is known to damage the kidneys, especially the proximal tubular cells that actively reabsorb Cd along with zinc, glucose and amino acids in the glomerular filtrate. Severe kidney damage, glycosuria and proteinuria are known outcomes after high dietary Cd intake ( $>200 \mu \mathrm{g} /$ day). Dietary Cd intake of 10-30 $\mu \mathrm{g} /$ day has been linked with reduced tubular reabsorption, chronic kidney disease, hypertension, coronary arterial and peripheral arterial diseases, macular degeneration, obesity-independent diabetes, and cancer. The links between diabetes, hypertension and end stage kidney disease (ESKD) are indisputable. ESKD requires dialysis or kidney transplant, an immense health care cost. This review adds to these connections by presenting the synergism of kidney $\mathrm{Cd}$ toxicity on blood pressure control and glucose homeostasis. Blood pressure control is mediated at least in part by cytochrome P450 (CYP) enzymes such as CYP4A11 and CYP4F2 that produce 20-hydroxyeicosatetraenoic acid (20-HETE), involved in salt balance in the kidney, and all are known to be altered during $\mathrm{Cd}$ exposure. The potential effects of $\mathrm{Cd}$ exposure on glucose reabsorption, inflammation, oxidative stress, and heme oxygenase activity are highlighted. The information presented offers strategies for mitigation of toxic effects of $\mathrm{Cd}$ through minimization of the food-chain transfer of $\mathrm{Cd}$, and modulation of mechanistic pathways altered by $\mathrm{Cd}$ exposure.
\end{abstract}

Keywords: cadmium; diabetes; end stage kidney disease; hypertension; 20-HETE

Tohoku J. Exp. Med., 2017 January, 241 (1), 65-87. C 2017 Tohoku University Medical Press

\section{Introduction}

The kidney is particularly at risk of injury from longterm use of therapeutic drugs and chronic exposure to environmental toxicants, especially the heavy metal cadmium (Cd) when it is present in the human diet (Gobe and Crane 2010; Soderland et al. 2010). The increased risk of injury has been attributable to large renal blood flow, and exposure to high solute concentrations of the glomerular filtrate (Nakhoul and Batuman 2011). Various transporters are expressed in this organ, especially in tubular epithelial cells to reabsorb nutrients and essential metals that would otherwise be lost through urinary excretion. Recently, reduction of glucose reabsorption in kidneys using inhibitors of sodium glucose co-transporter 2 (SGLT2) has emerged as a new strategy for the management of hyperglycemia, and thus a novel class of anti-diabetic drugs (Wilding 2014). Unexpectedly, such renal glucose reabsorption inhibition shows promise for weight reduction and blood pressure control (Vallon 2015; Reed 2016). This new discovery provides evidence linking SGLT2 activity in kidneys to the role of the kidneys in blood pressure control, demonstrated in early 1970s (Crowley and Coffman 2014). The enzymes of the cytochrome P450 (CYP) superfamily, especially of the CYP4 family (CYP4A11 and CYP4F2) in human kidneys have also been linked to the role of the kidneys in systemic blood pressure regulation (Satarug et al. 2006; Fan et al. 2015). The CYP4A11 and CYP4F2 enzymes catalyse ๑-hydroxylation of the arachidonic acid (Lasker et al. 2000) to produce 20-hydroxyeicosatetraenoic acid (20-HETE), involved in regulation of salt balance in the kidney (Wu et al. 2014a; Fan et al. 2015). CYP4F2 and CYP4F3B also catalyze the inactivation of leukotriene $\mathrm{B} 4$, a potent inflammatory agent, suggesting their role in tissue inflammation (Johnson et al. 2015).

$\mathrm{Cd}$ is a recognized food contaminant, and a constituent of cigarette smoke, and polluted air (ATSDR 2012; Satarug and Moore 2012; Satarug et al. 2010). For non-smokers,

Received April 13, 2016; revised and accepted January 8, 2017. Published online January 28, 2017; doi: 10.1620/tjem.241.65.

Correspondence: Soisungwan Satarug, M.C.H., Ph.D., Centre for Kidney Disease Research, Translational Research Institute, The

University of Queensland, Kent Street, Woolloongabba, Brisbane 4102, Australia.

e-mail: sj.satarug@yahoo.com.au 
diet is a major $\mathrm{Cd}$ source, while tobacco is an additional source for those who smoke (Satarug et al. 2013). Women of reproductive age and children are at greatest risk of $\mathrm{Cd}$ toxicity because of their enhanced gastrointestinal and pulmonary absorption rates for Cd (Barregard et al. 2010; Meltzer et al. 2010; Suh et al. 2016). After deposition in the kidney, an extremely small amount of $\mathrm{Cd}$ is excreted in urine, due to a lack of excretory mechanisms. Cd accumulates extensively in kidney cortex (Satarug et al. 2002). There are no therapeutically effective metal chelating agents for reducing $\mathrm{Cd}$ levels in kidneys. Cd-linked kidney damage presumably causes a reduction in tubular reabsorption of nutrients (glucose, amino acids, zinc, calcium), and low molecular weight proteins, notably $\beta 2$-microglobulin $(\beta 2$ $\mathrm{MG}), \alpha 1-$ microglobulin $(\alpha 1-\mathrm{MG})$, and retinol binding protein (RBP) (Honda et al. 2010; Wallin et al. 2014). Consequently, elevated urinary levels of these solutes are often used to reflect tubular malfunction. In addition, numerous adverse health outcomes, including macular degeneration (Wu et al. 2014b; Kim et al. 2014; Kim et al. 2016), and cancer of various sites, have been associated with chronic dietary Cd intake (Satarug et al. 2016).

The links between $\mathrm{Cd}$ exposure, diabetes, hypertension and end stage kidney disease (ESKD) are indisputable. In the present review, we provide an update of epidemiologic evidence for globally widespread $\mathrm{Cd}$ exposure and the wide range of diversity of $\mathrm{Cd}$ toxicity, with a focus on the studies linking dietary $\mathrm{Cd}$ exposure to kidney injury, chronic kidney disease (CKD), hypertension, and diabetes. We highlight causes and sources of dietary $\mathrm{Cd}$ exposure together with an update of the food-to-kidney pathway. Cd toxicity and exposure assessments, and the pitfalls of using total diet study to estimate dietary $\mathrm{Cd}$ exposure, are discussed. We review the studies that unravel potential mechanisms underlying toxic effects of $\mathrm{Cd}$ exposure in an effort to identify a potential means for exposure minimization and toxicity mitigation strategies.

\section{Cadmium -from soils to dinner plate}

$\mathrm{Cd}$ is present in trace amounts in most soils, rocks and waters, while high $\mathrm{Cd}$ levels are found in lead $(\mathrm{Pb})$ - and zinc-ores, some phosphate rocks, and rock phosphate fertilizers (Satarug et al. 2003; Dziubanek et al. 2015). Contamination of rice paddies by $\mathrm{Cd}$ from zinc mining discharge is a known cause of Itai-itai disease outbreak in the Jinzu river basin of Japan (Aoshima 1987) with sporadic cases being observed after decades of soil restoration (Horiguchi et al. 2010). Phosphate fertilizers have long been considered as a source of $\mathrm{Cd}$ input to agricultural soils that can lead to an increased dietary $\mathrm{Cd}$ exposure in consumers (Schroeder and Balassa 1963). This is because Cd is non-biodegradable, highly persistent in the environment, and it has high soil-to-plant transfer rates (Pizzol et al. 2014). Measured levels of $\mathrm{Cd}$ in agricultural produce vary widely, depending on plant varieties, soil types, growing conditions and agricultural methods (Callan et al. 2014;
Rahman et al. 2014). Filter feeder animals (e.g. oysters and scallops), and certain plant species (e.g. spinach, Romaine lettuce, soybeans, peanuts, tobacco) have the ability to bioaccumulate large $\mathrm{Cd}$ amounts without apparent toxicity, and they are known as Cd hyper-accumulators. Since Cd accumulates particularly in the kidney and liver of animals, offal (organ meat) contains relatively higher amounts of $\mathrm{Cd}$, compared to muscle (meat). Fish containing small quantities of $\mathrm{Cd}$ do not tend to be a major dietary $\mathrm{Cd}$ source. The Long Island Study of Seafood consumption found only a marginal increase in blood Cd levels among self-reported high consumers of salmon (Guan et al. 2015). In stark contrast, frequent consumption of oysters results in considerably high blood and urinary Cd levels (Copes et al. 2008) as does habitual consumption of animal offal (Madeddu et al. 2011). As can be expected, foods that are frequently consumed in large quantities such as staples rice, potato, and wheat, leafy salad vegetables, and cereal crops could be the most significant dietary $\mathrm{Cd}$ sources. There are particular concerns about the intake of $\mathrm{Cd}$ for vegetarians and also those who habitually consume diets high in $\mathrm{Cd}$ due to high consumption of animal offal, shellfish, and some seafoods. Considerable amounts of $\mathrm{Cd}$ (up to $1.46 \mu \mathrm{g}$ per $15 \mathrm{mg} \mathrm{Zn,} \mathrm{a}$ daily recommended dietary allowance) found in zinc supplements have also raised a concern for users (Krone et al. 2001).

\section{Cadmium -from dinner plate to kidney cell toxicity}

Variable percentages of $\mathrm{Cd}$ in food (0.1-10\%) are absorbed through gastrointestinal tract (GIT), depending on the individual physiological state, nutritional status and dietary habits (Satarug et al. 2000; Vesey 2010; ATSDR 2012). Cd absorption can be significantly elevated in certain individuals, such as pregnant, infants, iron deficient, and the malnourished (a further detail in section 7.2). The divalent metal transporter, DMT1, which is the primary iron (Fe) transporting protein in GIT, is regarded as a major carrier for Cd (Gunshin et al. 1997; Thevenod and Wolff 2016). DMT1 is highly expressed in the GIT and has the same high affinity for $\mathrm{Cd}$ as it does for $\mathrm{Fe}(\mathrm{Km} 0.5 \sim 1 \mu \mathrm{M})$ (Gunshin et al. 1997). Other transporters possibly involved include the zinc transporter, ZIP14, a metal/bicarbonate symporter, which is highly expressed by the intestinal enterocytes and can readily transport free $\mathrm{Cd}$, and the $\mathrm{Ca}^{2+}$ selective channel, TRPV6, which appears especially important in Cd uptake, when diets are low in calcium (Girijashanker et al. 2008;Kovacs et al. 2011). It is unclear how $\mathrm{Cd}$ reaches the basolateral cell surface, and then exits from the enterocyte into the circulation. The cytoplasmic calcium binding protein, calbindin may be involved in cytoplasmic transport, and the Fe exporter protein, ferroportin1 (FPN1) is possibly responsible for cellular Cd efflux. FPN1 is present at enterocyte basolateral membrane but evidence for a definitive role is lacking. Complexes of Cd with peptides and small proteins can also be directly absorbed in 
GIT possibly by transcytosis (Fujita et al. 1993).

Following GIT absorption, Cd is thought to be loosely bound to plasma proteins such as albumin and carried via the portal blood system to the liver cells, where it induces the synthesis of a specific metal binding protein, metallothionin (MT, MW 7kDa), and becomes tightly bound to this protein. In this form, the liver is protected from Cd-induced toxicity. MT-Cd complexes are gradually released by the liver. Following acute $\mathrm{Cd}$ exposure the liver is the prime site of toxicity. However, with chronic exposure, high levels of $\mathrm{Cd}$ do not remain in the liver but redistribute to the kidney, where it accumulates in tubular epithelial cells (Prozialeck and Edwards 2012). Cd that enters the systemic blood circulation can either be loosely associated with albumin, amino acids, glutathione or tightly bound to MT. Only free Cd is available for uptake by cells and as such Cd which is only loosely bound is able to dissociate and then bind to other target molecules on the cell surface and enter the cell. Cd bound tightly to MT is not available for uptake by most cells. The cells of the renal proximal tubules (PT) are the exception because they possess specialised receptors for protein endocytosis, namely cubulin and megalin. For these reasons, $\mathrm{Cd}$ accumulates particularly in the PT cells. It is also worth noting that most of the circulating $\mathrm{Cd}$ is actually concentrated in erythrocytes, where it is bound to MT or haemoglobin. Less than $10 \%$ is in the plasma, where it is associated with plasma proteins.

The S1-segment of renal PT is the tubular segment, which is specialized in reabsorption of nutrients and essential elements such as iron, calcium, and zinc in the filtrate. Renal reabsorption is a highly efficient retrieval mechanism, given that PT cells have large luminal surface area (numerous microvilli), high abundance of mitochondria, and simple tight junctions (Gobe and Crane 2010; Vallon 2015; Reed 2016). In studies with microinjection in rat proximal tubules (Klassen et al. 2004; Bridges and Zalups 2005), an approximate of $70-90 \%$ of ${ }^{109} \mathrm{Cd}$ was reabsorbed in the $\mathrm{S} 1$-segment, and such ${ }^{109} \mathrm{Cd}$ reabsorption was reduced, when zinc or iron was co-injected with $\mathrm{Cd}$. In a recent study with perfused rabbit proximal tubules (Wang et al. 2010), Cd reabsorption was inhibited by high concentrations of zinc, iron and calcium. The majority of $\mathrm{Cd}$ in the glomerular filtrate is bound to protein. Thus, it is suggested that $\mathrm{Cd}$ reabsorption is mediated by receptor-mediated endocytosis, involving the multi-ligand receptors, megalin and cubulin (Wolff et al. 2006; Thevenod and Wolff 2016). These two multi-ligand receptors are localized to the apical membrane of PT cells, and they are responsible for reabsorption of the all proteins, notably albumin and MT, present in the glomerular filtrate (Nielsen et al. 2016).

Upon internalization, the ligands (albumin and MT) are degraded by endosomal and lysosome protease enzymes, while the receptors (megalin and cubulin) are recycled to the plasma membrane. Subsequent to the degradation of ligands, $\mathrm{Cd}$ ions are released into the cytoplasm as unbound or free ions, which are capable of causing toxicity. The lysosomal release of free $\mathrm{Cd}^{2+}$ ions may be mediated by DMT1 that is localized to the endosome and the lysosome (Abouhamed et al. 2006). The free $\mathrm{Cd}^{2+}$ ion release mechanism could explain enhanced toxicity of $\mathrm{Cd}$ in kidneys of people with iron deficiency, the result of consumption of diet low in iron (a further detail section 7.2). In rat kidneys, DMT1 expression was seen only in endosomes and lysosomes (Ferguson et al. 2001; Abouhamed et al. 2006), but in mouse kidneys, DMT1 was localized to the apical membrane of PT cells, where iron and presumably Cd can be reabsorbed (Canonne-Hergaux and Gros 2002). These data suggest potential species differences in iron and Cd reabsorption by mouse vs. rat kidneys. Role for DMT1 in Cd toxicity has been shown in a PT cell culture model, where MT-Cd induced cell death was prevented after knockdown of DMT1expression (Abouhamed et al. 2007). In distinction from PT cells, DMT1 is expressed at the apical membrane of distal tubular (DT) cells (Ferguson et al. 2001), thereby suggesting DMT1 role in Cd reabsorption in the distal tubules.

The role for zinc transporters such as ZIP8, ZIP10, and ZIP14 in Cd reabsorption by kidneys has been reported. Early works indicated that ZIP8 and ZIP14 could mediate cellular uptake of zinc, manganese and $\mathrm{Cd}$ (He et al. 2009; Himeno et al. 2002). In a recent study, the transgenic mice with three more copies of the ZIP8 gene were found to accumulate twice as much $\mathrm{Cd}$ in the kidney after $\mathrm{Cd}$ exposure, and the PT from these mice had elevated ZIP8 expression levels at the apical membrane, accounting for their high sensitivity to Cd toxicity (Nebert et al. 2012). ZIP10 has been found in high abundance in renal cortical epithelial cells, suggesting the potential role for this zinc transporter in Cd reabsorption (Kaler and Prasad 2007). There is little evidence for an exit route for $\mathrm{Cd}$ once it has entered PT cells. The majority of $\mathrm{Cd}$ in PT cell is sequestered in MT, and only a small proportion of $\mathrm{Cd}$ is found at the basolateral membrane (Thevenod 2003). It is suggested that FPN1 may mediate the efflux of $\mathrm{Cd}$, but solid evidence is still lacking. A lack of exit route means that $\mathrm{Cd}$ is retained in kidneys for a long time. An average halftime of $\mathrm{Cd}$ in kidneys is 14 yrs, ranging from 9 to 28 years in a Japanese study (Suwazono et al. 2009) and it is 45 years in a study of Swedish kidney transplant donors (Fransson et al. 2014).

\section{Cadmium -Assessment of exposure}

\section{Total diet study (TDS)}

Food crops grown on Cd-containing soils constitute a major source of non-workplace exposure worldwide. Hence, the metal residues data, together with a national nutritional and food consumption survey known as the total diet study (TDS), were used to estimate dietary Cd intake for a given country. The TDS, known also as the "market basket survey", involves collection of samples of foodstuffs from supermarkets and retail stores for quantitation of various food additives, pesticide residues, contaminants, and 
nutrients in foods (Callan et al. 2014; Awata et al. 2016). The TDS is a food safety monitoring program, conducted by food authority agencies such as the U.S. Food and Drug Administration (FDA), the European Food Safety Agency (EFSA) and the Food Standards of Australia and New Zealand (FSANZ), previously known as the Australia and New Zealand Food Authority (ANZFA). However, distribution of $\mathrm{Cd}$ in foods is skewed as is the case with most contaminants that reach foods through unpredictable processes. Consequently, the TDS tends to largely underestimate dietary $\mathrm{Cd}$ exposure levels. More importantly, dietary intake estimates, derived from the TDS, do not appear to reflect dietary $\mathrm{Cd}$ intake of each individual person. For instance, a study of 1,764 post-menopausal Danish women (Vacchi-Suzzi et al. 2015) estimated mean dietary Cd intake of $14 \mu \mathrm{g} /$ day, with leafy vegetables and soy-based products being the main dietary Cd sources. This Danish TDS has shown a marginal correlation between estimated dietary $\mathrm{Cd}$ intakes and $\mathrm{Cd}$ levels in urine samples from women who participated in a study.

Likewise, estimates of dietary Cd intake, based on food $\mathrm{Cd}$ content and food consumption data from the U.S. FDA 2006-2011 TDS, showed no correlation with blood Cd levels among an Asian subpopulation in the U.S. National Health and Nutrition Examination Surveys (NHANES) 2011-2012 (Awata et al. 2016). Such minimal correlation between the TDS estimated dietary $\mathrm{Cd}$ intakes and wellfounded biomarkers of $\mathrm{Cd}$ exposure (blood and urinary $\mathrm{Cd}$ levels) means that no effects of $\mathrm{Cd}$ could be observed in epidemiological studies that rely solely on the TDS data. For these reasons, blood and urinary Cd levels, rather than estimated intake from the TDS, should be used in health risk assessment of dietary $\mathrm{Cd}$ exposure (reviewed in Satarug et al. 2016). The TDS does, however, provide a reasonable method to gauge a relative contribution of each food item to total dietary $\mathrm{Cd}$ intake. For instance, staple foods such as potatoes and wheat each constitute $46.7 \%$ and $16.3 \%$, respectively, of the total $\mathrm{Cd}$ in a typical Australian diet (Satarug et al. 2003). Other sources of $\mathrm{Cd}$ and its percentage contribution to the total $\mathrm{Cd}$ intake include cocoa $(12.5 \%)$, meat $(7.3 \%)$, vegetables $(4.4 \%)$, peanuts $(3.1 \%)$ and crustaceans plus mollusc $(4.8 \%)$. The contribution of each food item to total $\mathrm{Cd}$ intake may also be useful in relative risk management and establishment of food standards, known as the Maximum Permissible Concentration (MPC).

Sand and Becker (2012) used 7-day food records from a survey of $>1,200$ adults in Sweden. They estimated a dietary $\mathrm{Cd}$ intake of $10.6 \mu \mathrm{g} /$ day for a $74-\mathrm{kg}$ average consumer, with $40-50 \%$ of dietary Cd coming from staple foods (potatoes and wheat), whereas for high consumers (dietary $\mathrm{Cd}$ exposure above the 95th percentile), estimated dietary exposure was $23 \mu \mathrm{g}$ /day, with additional Cd coming from seafood and spinach. Data derived from the 2nd French TDS (Arnich et al. 2012) showed a dietary Cd intake of $11.2 \mu \mathrm{g} / \mathrm{day}$ for an average food consumer and $18.9 \mu \mathrm{g} /$ day for a high consumer. For the average con- sumer, $35 \%$ came from bread products and another $26 \%$ from potatoes-based products. The additional $\mathrm{Cd}$ came from consumption of molluscs and crustaceans in the high consumer group. Dietary $\mathrm{Cd}$ exposure in the 2nd French TDS (2007-2009) was four times higher than that of the 1st TDS (2000-2004). The Cd concentrations were reported for the different food groups; crustaceans and molluscs had the highest $\mathrm{Cd}$ content $(0.167 \mathrm{mg} / \mathrm{kg})$, followed by offal $(0.053 \mathrm{mg} / \mathrm{kg})$, sweet and savoury biscuits $(0.030 \mathrm{mg} / \mathrm{kg})$ and cereal bars and chocolate $(0.029 \mathrm{mg} / \mathrm{kg})$. Data were not reported on the variations in dietary habits. Likewise, the TDS did not report the body status of essential metals, which governs $\mathrm{Cd}$ absorption, and resultant toxicity.

\section{Urinary cadmium levels as a measure of long-term expo- sure}

Urinary Cd levels show substantial correlation with kidney Cd levels, and other determinants of kidney Cd levels such as age, gender, smoking, and body status of essential metals. A urinary $\mathrm{Cd}$ level thus serves as a measure of kidney burden and a biomarker of long-term exposure for each individual person. In the general population, blood Cd is considered a good estimate of body burden because population blood $\mathrm{Cd}$ levels correlate with urine $\mathrm{Cd}$ levels (Tellez-Plaza et al. 2010; Wu et al. 2014b). Blood Cd is a better estimate of exposure for the elderly, people with diabetes, hypertension, and heavy smokers because the high prevalence of kidney dysfunction in these people may bias associations between their urine $\mathrm{Cd}$ levels and health outcomes. Measurement of urinary and/or blood Cd concentration has been included in a large bio-monitoring program such as the U.S. NHANES. Consequently, NHANES is a rich data source for investigating $\mathrm{Cd}$ exposure that can be generalized to the U.S. population. Urinary $\mathrm{Cd}$ levels among the NHANES 1999-2008 participants, 20-85 yrs of age, indicated overall $\mathrm{Cd}$ exposure prevalence of $94-98 \%$ in non-smokers and $96-99 \%$ in smokers (Riederer et al. 2013). Overall $\mathrm{Cd}$ exposure prevalence among NHANES 20072012 participants, aged $\geq 20$ yrs, was $91.9 \%$ (Buser et al. 2016).

Fig. 1 is a diagram showing preferential kidney $\mathrm{Cd}$ accumulation, based on data from Australian autopsy study (Satarug et al. 2001, 2002). To demonstrate kidney Cd peak levels, data from those, aged 40-49 yrs have been chosen, which showed average Cd levels of $0.30,1.45$, and 25 $\mu \mathrm{g} / \mathrm{g}$ wet tissue weight in lung, liver and kidney cortex samples, respectively. Cd accumulation in kidney cortex is the most extensive. Kidney and liver Cd combined comprises two third of total body burden, of which $0.005 \%$ is excreted in urine. For the sample group shown, estimated mean blood Cd level is $1 \mu \mathrm{g} / \mathrm{L}$, while estimated mean urinary $\mathrm{Cd}$ level is $1.25 \mu \mathrm{g} / \mathrm{g}$ creatinine. A group of pregnant, non-smoking Australian women (mean age $32 \mathrm{yrs}$ ) had mean (range) urinary Cd levels of $0.78(0.16-4.65) \mu \mathrm{g} / \mathrm{g}$ creatinine (Hinwood et al. 2013), but a group of older, nonsmoking women (mean age $60 \mathrm{yrs}$ ) showed a tendency to 


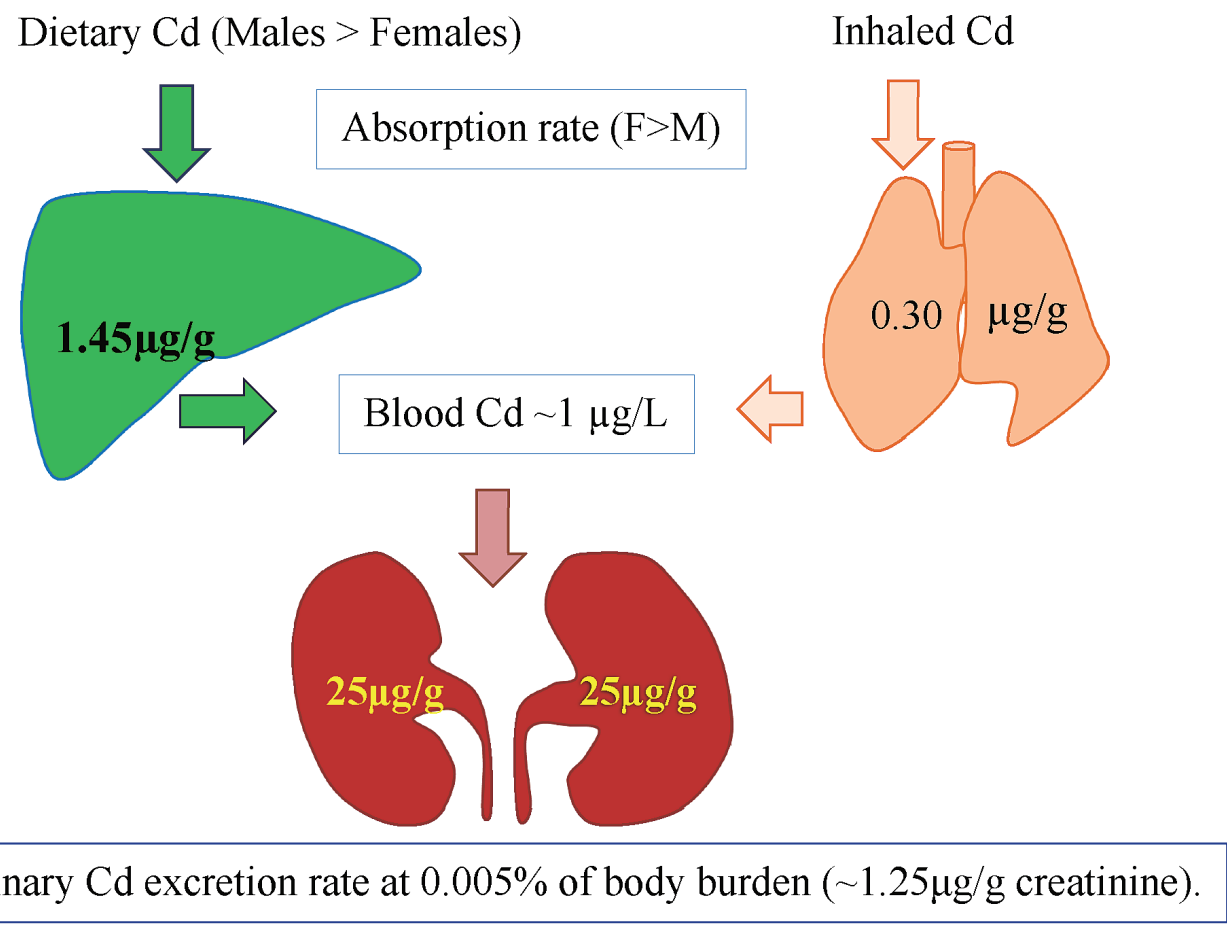

Fig. 1. Tissue differentiated cadmium accumulation and urinary cadmium excretion as a measure of body burden. Diet is the main route of human exposure to $\mathrm{Cd}$. Men tend to consume greater amounts of food (Cd source) than women, but women generally have greater $\mathrm{Cd}$ absorption rates, attributable to lower body iron status than men. $\mathrm{Cd}$ accumulation in kidney cortex is the most extensive. Lung, liver and kidney cortex samples from Australians, aged 40-49 yrs, contained $\mathrm{Cd}$ at $0.30,1.45$, and $25 \mu \mathrm{g} / \mathrm{g}$ wet tissue weight, respectively. Kidney and liver Cd levels, combined, comprise two third of total body burden, of which $0.005 \%$ is excreted in urine. Urinary Cd levels correlate with body burden, and thus serve as a measure of long-term exposure. For the Australian sample group shown, estimated mean blood $\mathrm{Cd}$ level is $1 \mu \mathrm{g} / \mathrm{L}$, while estimated mean urinary Cd level is $1.25 \mu \mathrm{g} / \mathrm{g}$ creatinine.

have lower urinary Cd levels (ranging from $<0.065$ to 1.03 $\mu \mathrm{g} / \mathrm{g}$ creatinine) (Callan et al. 2015). The lower urinary Cd levels in the older group may reflect an increased exposure in more recent times.

\section{Cadmium -Assessment of kidney toxicity}

\section{Tubular injury and functional impairment}

For the general population, the most frequently reported effect of $\mathrm{Cd}$ exposure is injury to tubular epithelial cells that actively reabsorb $\mathrm{Cd}$ from the glomerular filtrate. Renal tubular cells are rich in mitochondria and heavily reliant on autophagy to maintain homeostasis (Havasi and Dong 2016), making them highly susceptible to Cd-induced apoptosis (Gobe and Crane 2010; Fujiwara et al. 2012). A large body of literature has consistently observed an increased risk of kidney toxicity, attributable to $\mathrm{Cd}$ exposure in the general populations worldwide. However, kidney toxicity of $\mathrm{Cd}$ exposure has been disputed and even dismissed in a few studies that reported no correlations between urinary $\mathrm{Cd}$ levels and biomarkers of toxicity such as kidney injury molecule-1 (KIM-1), RBP, or $\beta 2-\mathrm{MG}$ (Chaumont et al. 2012). Cd exposure levels among the people in this study may be well below "critical" kidney $\mathrm{Cd}$ levels. However, we argue that assessment of $\mathrm{Cd}$ toxicity should be based on a battery of biomarkers before any conclusions can be drawn. Indeed, Wallin et al. (2014) observed a positive correlation between kidney Cd levels and urinary $\alpha 1-\mathrm{MG}$ levels, and they suggest that urinary $\alpha 1-\mathrm{MG}$ could serve as a more sensitive biomarker for kidney toxicity, compared with KIM-1, RBP, and $\beta 2-\mathrm{MG}$, which do not correlate with kidney $\mathrm{Cd}$ levels in chronic low-level exposure conditions. Likewise, Callan et al. (2015) reported no correlation between levels of $\mathrm{Cd}$ and KIM-1 in urine samples from a group of Australian women, $50-83$ yrs of age (mean 59.6 yrs) with urinary Cd levels ranging from $<0.065$ to $1.03 \mu \mathrm{g} / \mathrm{g}$ creatinine, but they found evidence for bone effects. Further, in the Japanese Takahata cohort, mild tubular impairment (urinary $\beta 2 \mathrm{MG}$ $\geq 300 \mu \mathrm{g} / \mathrm{g}$ creatinine) was associated with an increased risk of having estimated glomerular filtration rate (eGFR) fall at high rates, i.e., $10 \mathrm{~mL} / \mathrm{min} / 1.73 \mathrm{~m}^{2}$ in 5 yrs (OR 1.79 , 95\% CI 1.07-2.99) (Kudo et al. 2011). Injury to and death of renal tubular epithelial cells can account for a reduction in tubular reabsorptive capacity (Gobe and Crane 2010; Fujiwara et al. 2012). The finding that people with impaired tubular function have high rates of GFR reduction supports the notion that the proximal tubular epithelium plays a critical role in the development and progression of CKD to ESKD (Nakhoul and Batuman 2011).

\section{Cadmium -chronic kidney disease}

CKD is defined as eGFR $<60 \mathrm{~mL} / \mathrm{min}$ per $1.73 \mathrm{~m}^{2}$ or 
urinary albumin to creatinine ratio $>30 \mathrm{mg} / \mathrm{g}$ creatinine. Prevalence of CKD among the 17,794 adults surveyed in the U.S. NHANES 1999-2006 with prehypertension and undiagnosed hypertension were $17.3 \%$ and $22.0 \%$, respectively, compared with $27.5 \%$ with diagnosed hypertension and $13.4 \%$ with normal blood pressure (Crews et al. 2010). Table 1 provides a summary of epidemiologic studies showing $\mathrm{Cd}$ exposure as a risk factor in $\mathrm{CKD}$, and two common disorders (diabetes and hypertension) that are closely linked with CKD development and progression to ESKD (Islam et al. 2009). Ferraro et al. (2010) found that urinary and blood
Cd levels greater than $1 \mu \mathrm{g} / \mathrm{L}$ were associated with $41-63 \%$ increase in risk of low GFR and albuminuria among the NHANES 1999-2006 adult participants. However, Cd exposure and low GFR connection became obscured, when urinary creatinine was used to correct for diluting effects of spot urine samples (Ferraro et al. 2010). This may suggest variability in renal function related to creatinine secretion. An association between blood Cd levels and low GFR has been evident from data of NHANES 2007-2012 participants, aged $\geq 20$ years, showing mean urinary Cd of 0.35 $\mu \mathrm{g} / \mathrm{L}$ and mean blood Cd of $0.51 \mu \mathrm{g} / \mathrm{L}$ (Buser et al. 2016).

Table 1. Cadmium as a risk factor in chronic kidney disease, diabetes and hypertension.

\begin{tabular}{|c|c|}
\hline Exposure outcomes/Study & Risk estimates \\
\hline $\begin{array}{l}\text { Kidney damage }^{\mathrm{a}} \text { and chronic kidney } \\
\text { disease, Ferraro et al. }(2010) \text {, U.S. } \\
\text { NHANES 1999-2006, } n 5426 \text {, aged } \geq 20 \\
\text { yrs. }\end{array}$ & $\begin{array}{l}\text { Blood Cd levels }>1 \mu \mathrm{g} / \mathrm{L} \text { and urinary } \mathrm{Cd}>1 \mu \mathrm{g} / \mathrm{L} \text { were } \\
\text { associated with chronic kidney disease (OR } 1.48,95 \% \text { CI } 1.01 \text { - } \\
2.17 \text { ), and kidney damage (OR } 1.4195 \% \text { CI } 1.10-1.82 \text { ). }\end{array}$ \\
\hline $\begin{array}{l}\text { Kidney damage and diminished kidney } \\
\text { function }{ }^{\mathrm{b}} \text {, Lin et al. (2014), U.S. } \\
\text { NHANES 2011-2012, } n 1545 \text {, aged } \geq 20 \\
\text { yrs. }\end{array}$ & $\begin{array}{l}\text { Blood Cd levels }>0.53 \mu \mathrm{g} / \mathrm{L} \text { were associated with diminished } \\
\text { kidney function (OR 2.21, 95\% CI 1.09-4.50) and kidney } \\
\text { damage (OR 2.04, 95\% CI 1.13-3.69). }\end{array}$ \\
\hline $\begin{array}{l}\text { Diabetes, Son et al. (2015), } n 719 \\
\text { Koreans, aged } 40-70 \text { yrs. }\end{array}$ & $\begin{array}{l}\text { Urinary levels Cd }>2 \mu \mathrm{g} / \mathrm{g} \text { creatinine were associated with } \\
\text { diabetes in men (OR } 1.81,95 \% \text { CI 1.05-3.12). }\end{array}$ \\
\hline $\begin{array}{l}\text { Pre-diabetes (abnormal fasting glucose) } \\
\text { and diabetes, Schwartz et al. (2003), } \\
\text { U.S. NHANES III (1988-1994, } n 8722 \text {, } \\
\text { aged } \geq 40 \text { yrs. }\end{array}$ & $\begin{array}{l}\text { Risk of pre-diabetes increases with Cd exposure in a dose- } \\
\text { dependent manner (OR } 1.48,95 \% \text { CI } 1.21-1.82 \text { and } 2.05,95 \% \\
\text { CI } 1.42-2.95 \text {, comparing urinary Cd } 1.00-1.99 \text { and } \geq 2 \text { vs. }<1 \\
\mu \mathrm{g} / \mathrm{g} \text { creatinine). Risk of diabetes increased with Cd exposure } \\
\text { (OR } 1.24,95 \% \text { CI } 1.06-1.45 \text { and } 1.45,95 \% \text { CI } 1.07-1.97) \text {, } \\
\text { comparing urinary cadmium } 1.00-1.99 \text { and } \geq 2 \text { vs. }<1 \mu \mathrm{g} / \mathrm{g} \\
\text { creatinine. }\end{array}$ \\
\hline $\begin{array}{l}\text { Pre-diabetes, Wallia et al. (2014), U.S. } \\
\text { NHANES 2005-2010, } n 2398 \text {, aged } \geq 40 \\
\text { yrs, without albuminuria, diabetes or } \\
\text { chronic kidney disease. }\end{array}$ & $\begin{array}{l}\text { Urinary Cd levels }>1.4 \mu \mathrm{g} / \mathrm{g} \text { creatinine were associated with } \\
\text { risk of pre-diabetes in non-smokers. Urinary Cd levels between } \\
0.7 \text { and } 0.9 \mu \mathrm{g} / \mathrm{g} \text { creatinine were associated pre-diabetic risk in a } \\
\text { fully adjusted model, including smokers and non-smokers. } \\
\\
\text { Pre-diabetic risk associated with Cd exposure is particularly } \\
\text { strong in old age group. }\end{array}$ \\
\hline $\begin{array}{l}\text { Pre-diabetes, Nie et al. (2016), China, } \\
n 5544 \text {, male and female adults. }\end{array}$ & $\begin{array}{l}\text { Blood Cd levels between } 0.81 \text { and } 2.94 \mu \mathrm{g} / \mathrm{L} \text { were associated } \\
\text { with pre-diabetic risk (OR } 1.19,95 \% \text { CI } 1.01-1.40 \text { ), while blood } \\
\text { Cd levels } \geq 2.95 \mu \mathrm{g} / \mathrm{L} \text { were associated with risk of pre-diabetes } \\
\text { (OR } 1.37,95 \% \text { CI } 1.14-1.63 \text { ) }\end{array}$ \\
\hline $\begin{array}{l}\text { Hypertension, Scinicariello et al. (2011) } \\
\text { U.S. NHANES 1999-2006, } n 16222 \text {, aged } \\
\geq 20 \text { yrs. }\end{array}$ & $\begin{array}{l}\text { Blood Cd levels } \geq 0.4 \mu \mathrm{g} / \mathrm{L} \text { were associated with hypertension } \\
\text { in Caucasian women (OR 1.54, 95\% CI 1.08-2.19) and } \\
\text { Mexican-American women (OR 2.38, 95\% CI 1.28-4.40). }\end{array}$ \\
\hline $\begin{array}{l}\text { Pre-hypertension and hypertension, Lee } \\
\text { and Kim (2012), Korean NHANES 2008- } \\
2010, n 5919 \text {, aged } \geq 19 \text { yrs. }\end{array}$ & $\begin{array}{l}\text { For women, a rise in blood Cd levels from } 0.73 \text { to } 1.57 \mu \mathrm{g} / \mathrm{L} \\
\text { was associated with hypertension (OR } 1.32,95 \% \text { CI } 1.15-1.50) \\
\text { and pre-hypertension (OR } 1.24,95 \% \text { CI } 1.08-1.42 \text { ). } \\
\text { For men, a rise in blood Cd levels from } 0.62 \text { to } 1.33 \mu \mathrm{g} / \mathrm{L} \text { was } \\
\text { associated with hypertension (OR } 1.19,95 \% \text { CI } 1.00-1.41 \text { ) and } \\
\text { pre-hypertension (OR } 1.23,95 \% \text { CI } 1.07-1.41 \text { ). }\end{array}$ \\
\hline $\begin{array}{l}\text { Hypertension, Lee et al. 2016, Korean } \\
\text { NHANES 2008-2013, } n 11979 \text {, aged } \geq 19 \\
\text { yrs. }\end{array}$ & $\begin{array}{l}\text { Mean blood Cd level was } 1.13 \mu \mathrm{g} / \mathrm{L} \text { in women, and it was } 0.79 \\
\mu \mathrm{g} / \mathrm{L} \text { in men. } \\
\text { A two-fold increase in blood Cd level was associated with } \\
\text { hypertension in men and women (OR } 1.25,95 \% \text { CI } 1.15-1.36) \\
\text { with a greater risk in women (OR } 1.40,95 \% \text { CI } 1.23-1.58)\end{array}$ \\
\hline
\end{tabular}

${ }^{\mathrm{a}}$ Urinary albumin to creatinine ratio $\geq 30 \mathrm{mg} / \mathrm{g}$ creatinine; ${ }^{\mathrm{b}}$ Estimated glomerular filtration rate $($ eGFR $)<60 \mathrm{ml} / \mathrm{min} / 1.73 \mathrm{~m}^{2}$.

NHANES, National Health and Nutrition Examination Survey; $n$, sample size; CI, Confidence interval; HR, Hazard ratio; OR = Odds ratio. 
Blood Cd levels $>0.53 \mu \mathrm{g} / \mathrm{L}$ were associated with an approximate two-fold increase in risk of diminished GFR (OR 2.21, 95\% CI 1.09-4.50) and of albuminuria (OR 2.04, 95\% CI 1.13-3.69) among adults enrolled in NHANES 2011-2012 (Lin et al. 2014). In a Korean study, an inverse association between blood Cd and GFR has been observed only in women (Hwangbo et al. 2011). Elevated blood Cd levels, but not blood $\mathrm{Pb}$ or blood $\mathrm{Hg}$, were associated with CKD in another Korean study (Kim et al. 2015). In this Korean study, a significant rise in CKD risk was observed for hypertensive subjects (OR 1.52, CI 95\% 1.05-2.19) and diabetic subjects (OR 1.92, 95\% CI, 1.14-3.25). These findings suggest that $\mathrm{Cd}$ exposure could increase $\mathrm{CKD}$ risk, especially in those with hypertension or diabetes (Kim et al. 2015). In a study of 590 Swedish women with median blood Cd of $0.34 \mu \mathrm{g} / \mathrm{L}$, Barregard et al. (2014) found that women with diabetes were at greater risk of kidney toxic effects of $\mathrm{Cd}$ exposure, compared to women without diabetes.

\section{Impaired glucose reabsorption}

Renal glucose reabsorption is mediated by SGLT2, located in cortical proximal tubular cells, where the bulk of glucose (an approximate of 160 to 180 gm per day) is reabsorbed and returned to systemic circulation, under normal physiological conditions (Wilding 2014; Vallon 2015). Impaired tubular reabsorption of glucose has been noted in high-dose exposure situations (Nishijo et al. 2004; Honda et al. 2010). Such increased urinary glucose excretion may be indicative of mitochondrial toxicity of $\mathrm{Cd}$ in proximal tubular cells, affecting oxidative phosphorylation and ATP output (Gobe and Crane, 2010). An association between urinary $\mathrm{Cd}$ and urinary citrate levels has been noted in a study of 168 highly exposed Thai subjects and 100 controls (Suvagandha et al. 2014). This Thai study suggested that $\mathrm{Cd}$ may have a direct effect on mitochondrial citrate metabolism because the strength of association between urinary $\mathrm{Cd}$ and citrate levels was maintained after adjustment for age, smoking status, and degree of tubular impairment (Suvagandha et al. 2014). Mitochondrial effects of in lowdose $\mathrm{Cd}$ exposure have also been noted in a Swedish study (Ellis et al. 2012), showing a positive correlation between urinary $\mathrm{Cd}$ levels and urinary excretion of the mitochondrial metabolites such as citrate, 3-hydroxyisovalerate, and 4-deoxy-erythronic acid. Intriguingly, risk of overweight is lower in Chinese subjects with higher $\mathrm{Cd}$ exposure (Nie et al. 2016), while an inverse association between $\mathrm{Cd}$ exposure levels and central obesity and BMI has been noted in the U.S. (Padilla et al. 2010; Jain 2013) and Canada (Garner and Levallois 2016) populations. These findings are consistent with reduction in weight after renal glucose reabsorption is diminished through administration of SGLT2 inhibitors (Vallon 2015).

\section{Cadmium and diabetic risk}

Rising incidence of type- 2 diabetes has been noted along with increasing prevalence of obesity. The increased risk of diabetes in obese people has been largely attributed to oxidative stress, chronic inflammation and liver complications due to obesity (Lumeng and Saltiel 2011). Nonalcoholic fatty liver disease (NAFLD) is a clinical manifestation of metabolic syndrome and insulin resistance, while non-alcoholic steatohepatitis (NASH) is closely associated with obesity and lipotoxicity (Cusi et al. 2012). Paradoxically, however, obese diabetic persons appear to have lower mortality risk, compared with lean (non-obese) diabetic persons (Engelmann et al. 2016). Exposure to Cd, especially of dietary origin, is the least expected and least recognized contributing factor in the global rising prevalence of diabetes. In early work, diabetic symptoms were induced in rats and mice after $\mathrm{Cd}$ administration (reviewed in Satarug and Moore 2012). More importantly, chronic Cd exposure has been associated with the pathologies seen in obesity. For instance, the NHANES 1988-1994 data show increased risk of liver inflammation, NAFLD and NASH among participants with elevated $\mathrm{Cd}$ exposure levels (Hyder et al. 2013).

Liver effects of $\mathrm{Cd}$ exposure mimic some effects of obesity, but, conversely, higher mortality has been observed among those with higher $\mathrm{Cd}$ body burden, compared with those with lower body Cd burden (Hyder et al. 2013). In NHANES 1999-2002 participants, shortening of leucocyte telomere lengths (a marker of oxidative stress) show an inverse association with $\mathrm{Cd}$ exposure (Zota et al. 2015), trunk fat, physical activity, and serum C-reactive protein (CRP) levels (Patel et al. 2016). These associations suggest oxidative stress and chronic inflammation among those with higher $\mathrm{Cd}$ exposure levels or with obesity (high trunk fat). We postulate that the effects of $\mathrm{Cd}$ exposure on diabetic risk are independent of obesity and that $\mathrm{Cd}$ exposure, at the very least, accounts for diabetes seen in lean persons. Evidence for obesity-independent effects of $\mathrm{Cd}$ exposure on diabetic risk comes from the following observations. Urinary $\mathrm{Cd}$ levels show an inverse association with central obesity among NHANES 1999-2002 participants (Padilla et al. 2010). Likewise, blood Cd levels showed an inverse association with BMI among NHANES 2003-2010 participants (Jain 2013). The Canadian Health Survey 2007-2011 has reported also that non-smokers with higher BMI had lower blood and urinary Cd levels (Garner and Levallois 2016). In a Chinese study (Nie et al. 2016), urinary Cd levels $\geq$ $2.95 \mu \mathrm{g} / \mathrm{g}$ creatinine were associated with lowered risk of overweight. Son et al. (2015) observed an inverse association between blood Cd levels and BMI in Korean men (40$70 \mathrm{yrs}$ ) with mean blood $\mathrm{Cd}$ of $1.7 \mu \mathrm{g} / \mathrm{L}$, and mean urinary $\mathrm{Cd}$ of $2.13 \mu \mathrm{g} / \mathrm{g}$ creatinine.

Positive association between cadmium exposure and diabetic risk: Evidence for a potential effect of Cd exposure on diabetic risk comes from a Korean study (Son et al. 2015), two cycles of the U.S. population studies; NHANES (1988-1994) and NHANES (2005-2010) (Schwartz et al. 2003; Wallia et al. 2014) and a Chinese study (see Table 1). 
In a study of 719 residents (aged 40-70 yrs) in high-exposure areas in Korea (Son et al. 2015), urinary Cd levels $>2$ $\mu \mathrm{g} / \mathrm{g}$ creatinine were associated with diabetic risk in men (OR 1.81, 95\% CI 1.05-3.12), compared with urinary $\mathrm{Cd} \leq$ $1 \mu \mathrm{g} / \mathrm{g}$ creatinine. Increased risks of pre-diabetes and diabetes were seen in both non-smokers and smokers in those two cycles, but a dose-response relationship between urinary $\mathrm{Cd}$ levels and risk of pre-diabetes and diabetes was seen only in the older cycle; NHANES 1988-1994 (Schwartz et al. 2003). In that study, a 1.48-fold increase in risk for pre-diabetes (OR 1.48, 95\% CI 1.21-1.82) was associated with urinary Cd levels of $1.00-1.99 \mu \mathrm{g} / \mathrm{g}$ creatinine, while a 2.05 -fold increase in risk (OR 2.05, 95\% CI $1.42-2.95)$ was associated with urinary Cd levels $\geq 2 \mu \mathrm{g} / \mathrm{g}$ creatinine, comparing with urinary Cd levels $<1 \mu \mathrm{g} / \mathrm{g}$ creatinine. For diabetes, a 1.24-fold increase in risk (OR 1.24, 95\% CI 1.06-1.45) was associated with urinary Cd levels of $1.00-1.99 \mu \mathrm{g} / \mathrm{g}$ creatinine, while a 1.45 -fold increase in risk (OR 1.45, 95\% CI 1.07-1.97) was associated with urinary Cd levels of $\geq 2 \mu \mathrm{g} / \mathrm{g}$ creatinine, comparing with urinary $\mathrm{Cd}$ levels $<1 \mu \mathrm{g} / \mathrm{g}$ creatinine. Lee et al. (2006) found the prevalence of diabetes in NHANES 1988-1994 participants correlated with blood $\mathrm{Cd}$ levels, together with hypercholesterolemia and serum levels of a marker of liver inflammation, alkaline phosphatase (ALP). Urinary Cd levels were associated with serum levels of another marker of inflammation, $\gamma$-glutamyl transferase (GGT). These findings suggest systemic inflammatory conditions among those with increased Cd body burden that may increase the risk of diabetes, similar to obesity (Lumeng and Saltiel 2011).

In NHANES 2005-2010, Wallia et al. (2014) found that an increased pre-diabetic risk among non-smokers were associated with urinary Cd levels above $1.375 \mu \mathrm{g} / \mathrm{g}$ creatinine, which were greater than the urinary levels associated with pre-diabetic risk in moderate and heavy smokers. Increased pre-diabetic risk among moderate smokers was associated with urinary Cd levels of $0.646 \mu \mathrm{g} / \mathrm{g}$ creatinine, while increased pre-diabetic risk among heavy smokers was associated with urinary $\mathrm{Cd}$ levels, ranging between 0.329 and $0.454 \mu \mathrm{g} / \mathrm{g}$ creatinine and $>0.711 \mu \mathrm{g} / \mathrm{g}$ creatinine. Wallia et al. (2014) have attributed the increased pre-diabetic risk in non-smokers to $\mathrm{Cd}$ toxicity in pancreatic $\beta$-cells, given a particularly strong association of urinary $\mathrm{Cd}$ (body burden) and risk of pre-diabetes in the elderly, whose Cd levels in $\beta$-cells could be expected to have exceeded a threshold limit due to longer exposure durations. Loss of pancreatic $\beta$-cells due to $\mathrm{Cd}$-induced apoptosis may thus be another mechanism for effects of $\mathrm{Cd}$ exposure on pre-diabetic risk. Yagihashi et al. (2016) reported a reduction in pancreatic $\beta$-cell volume density in both a diabetic, obese American group and diabetic, lean Asian (Japanese and Korean) groups, but compensatory hyperplasia of pancreatic $\beta$-cells has been evident only in the diabetic, obese American group. These observations may explain lower mortality among diabetic obese people, compared with diabetic lean persons (Engelmann et al. 2016). In a Chines population study ( $\mathrm{n}=5,544)$, Nie et al. (2016) observed risk of pre-diabetes increases with $\mathrm{Cd}$ exposure in a dosedependent manner (OR 1.19, 95\% CI 1.01-1.40 and OR 1.37, 95\% CI 1.14-1.63), comparing blood Cd 0.81-2.94, $\geq 2.95$ vs. $\leq 0.80 \mu \mathrm{g} / \mathrm{L}$. As can be expected, a synergy between obesity and high $\mathrm{Cd}$ exposure levels is evident from this Chinese study, showing higher risk of pre-diabetes in obese Chinese (OR 2.33, 95\% CI 1.10-4.94), compared with non-obese Chinese with similarly high blood Cd levels (OR 1.44, 95\% CI 1.15-1.82).

Lack of association between cadmium exposure and diabetic risk: In a Swedish cohort (a mean follow-up 15.2 years) of 4,585 persons, aged 46-67 yrs, who had no history of diabetes (Borne et al. 2014), blood Cd levels were positively associated with $\mathrm{HbAlc}$ levels in former smokers and current smokers, but they were not associated with incidence of diabetes in men or women. In the other study (Barregard et al. 2013), blood and urinary Cd levels were not associated with insulin production, blood glucose, $\mathrm{HbA1c}$, or changes in HbA1c in a 5.4-year follow-up of three groups of Swedish women, aged 64 yrs (215 with diabetes, 207 with impaired fasting blood glucose, and 194 controls). Obviously, this study was biased towards a single specific age (64 yrs). Consequently, the finding could not be generalized to the population. Comparing the above three groups, increased susceptibility to kidney Cd toxicity (demonstrated by albuminuria) was seen in a diabetic group (Barregard et al. 2014). In a study of 2,242 adults (75.1\% non-smokers, mean age 53 yrs) in Wuhan, China, Feng et al. (2015) found urinary $\mathrm{Pb}$ levels were associated with impaired fasting blood glucose levels, but urinary Cd levels were not associated with diabetic risk or impaired fasting blood glucose levels. In addition, urinary zinc, molybdenum and tungsten levels were associated with increased risk of diabetes in a dose-dependent manner. Low prevalence of diabetes $(9.7 \%)$ and of impaired fasting glucose (11.6\%) in this Chinese sample population (Feng et al. 2015) means that sample size of 2,242 would not be likely to provide sufficient power to demonstrate $\mathrm{Cd}$ exposure effects.

\section{Cadmium and hypertension}

One of the most widely recognised consequences of extensive kidney damage is hypertension, and hypertension of such renal origin is associated mostly with the reninangiotensin system of blood pressure control (Crowley and Coffman 2014; Ohashi et al. 2016). While hypertension due to frank renal pathology is relatively well understood, much milder kidney pathology may also cause more subtle, hitherto unsuspected and earlier changes. In the Takahata cohort, urinary $\beta 2-\mathrm{MG}$ levels $\geq 145 \mu \mathrm{g} / \mathrm{g}$ creatinine were associated with a greater risk of hypertension, compared with urinary $\beta 2-M G$ levels $\leq 84.5 \mu \mathrm{g} / \mathrm{g}$ creatinine (Mashima et al. 2011), thereby suggesting a link between mild tubular impairment and high blood pressure, also seen in a Thai study (Satarug et al. 2005). In the U.S. population study, Scinicariello et al. (2011) analysed data from 16,222 partic- 
ipants, aged $\geq 20$ years, enrolled in NHANES 1999-2006, and they confirmed the positive association of blood $\mathrm{Cd}$ levels and blood pressure levels in women. Because of a sufficiently large database, Scinicariello et al. (2011) have further shown that blood Cd levels $\geq 0.4 \mu \mathrm{g} / \mathrm{L}$ were associated with increased risk of hypertension in Caucasian women (OR 1.54, 95\% CI 1.08-2.19), and in MexicanAmerican women (OR 2.38, 95\% CI 1.28-4.40). Association of blood $\mathrm{Cd}$ and hypertension in Black women, and men of all three racial groups (Caucasian, Black, and Mexican American) did not reach statistical significance. Caucasian and Mexican-American women appeared to be more susceptible to pressor effects of $\mathrm{Cd}$ exposure than Black women. Lee and Kim (2012) found blood Cd levels were associated with elevated diastolic blood pressure in a Korean population survey $(\mathrm{n}=5,919$, aged $\geq 20 \mathrm{yrs})$, known as Korean National Health and Examination Survey (Korean NHANES 2008-2010). Women and men in the highest quartile of blood $\mathrm{Cd}$ had 2.243 and $1.975 \mathrm{mmHg}$ higher diastolic pressure than those in the lowest quartile of blood $\mathrm{Cd}$ and doubling of blood $\mathrm{Cd}$ was associated with an increased risk of hypertension and pre-hypertension in both men and women. For women, a rise in blood Cd levels from 0.73 to $1.57 \mu \mathrm{g} / \mathrm{L}$ was associated with hypertension (OR 1.32, 95\% CI 1.15-1.50) and pre-hypertension (OR $1.24,95 \%$ CI 1.08-1.42). For men, a rise in blood Cd levels from 0.62 to $1.33 \mu \mathrm{g} / \mathrm{L}$ was associated with hypertension (OR 1.19, 95\% CI 1.00-1.41) and pre-hypertension (OR $1.23,95 \%$ CI 1.07-1.41). In the Korean NHANES 2008$2013(\mathrm{n}=11,979$, aged $\geq 19 \mathrm{yrs})$, Lee et al. (2016) reported that a two-fold increase in blood Cd levels and men were associated with an increased risk of hypertension (OR = $1.25,95 \% \mathrm{CI}=1.15-1.36$ ), with a greater risk in women $(\mathrm{OR}$ Mean $=1.40,95 \% \mathrm{CI}=1.23-1.58)$, given that women had higher mean blood $\mathrm{Cd}$ than men $(1.13$ vs. $0.79 \mu \mathrm{g} / \mathrm{L})$. In groups of 276 women and 165 men in Cd contamination areas, Chen et al. (2015) reported that high blood Cd levels correlated with systolic hypertension in both men and women. They estimated benchmark dose for blood $\mathrm{Cd}$ of 1 $\mu \mathrm{g} / \mathrm{L}$ to be associated with increased risk of systolic hypertension and benchmark dose for blood Cd of $1.7 \mu \mathrm{g} / \mathrm{L}$ to be associated with an increased risk of diastolic hypertension.

Only a few studies reported an association between urinary $\mathrm{Cd}$ and blood pressure levels. This could be due to use of spot urine samples that require adjustment with urinary creatinine levels, shown to be problematic under certain circumstances. In the study by Ferraro et al. (2010), an association of urinary $\mathrm{Cd}$ and risk of $\mathrm{CKD}$ became obscured when creatinine was used to correct for diluting effects of spot urine samples. Urinary creatinine levels are associated with covariate factors such as age and BMI. Therefore, specific gravity correction of urinary $\mathrm{Cd}$ concentrations has been used in multivariate analysis to evaluate effects of $\mathrm{Cd}$ exposure on blood pressure. In the Strong Heart Study (Franceschini et al. 2016), higher urinary Cd levels were associated with higher systolic blood pressure among
American Indian participants ( $\mathrm{n}=3,714$, mean age $56 \mathrm{yrs}$ ), after adjustment for age, sex, geographic area, body mass index, smoking and kidney function. Of note, effects of $\mathrm{Cd}$ exposure on hypertension risk, seen in American Indians, were independent of smoking exposure. Because hypertension is both a cause and a consequence of $\mathrm{CKD}$, a longitudinal study is required to demonstrate that mild kidney injury after $\mathrm{Cd}$ exposure precedes high blood pressure development.

\section{Kidney CYP4 enzymes, 20-HETE and hypertension}

The kidneys are extra-hepatic organs that express high abundance of cytochrome P450 (CYP) enzymes, especially those of the CYP4A and CYP4F subfamilies such as CYP4A11, CYP4F2, CYP4F3, CYP4F11 and CYP4F12 (Fan et al. 2015). A carcinogen activating enzyme CYP2E1 is expressed also in human kidneys (Sasso et al. 2013). By immunohistochemistry, we have observed CYP2E1 expression along with CYP2B6, CYP3A4, and CYP4A11 in the cortical proximal tubular epithelial cells and to a lesser extent in distal tubular cells (Boonprasert et al. 2016). Distinctively, CYP4F2 was prominently expressed in proximal tubular cells as well as in glomeruli. Intriguingly, differential expression patterns of metallothionein (MT) and heme oxygenase-1 (HO-1) was also evident. HO-1 is localized to the proximal and distal tubular epithelial cells, while MT was predominantly localized to proximal tubular cells with little evidence of its expression in the glomeruli, distal tubules, or associated interstitial and vascular elements. The distal tubule (DT) could thus be the segment of nephron that is at risk of $\mathrm{Cd}$ toxicity because of lower expression of MT than the proximal tubule, in which both MT and HO-1 are expressed. $\mathrm{Na} / \mathrm{K}$-ATPase, a primary Cd toxicity target (Thevenod and Friedmann 1999), is expressed in the DT in the highest density, especially in the basolateral membrane (Subramanya and Ellison 2014).

In human kidneys, CYP4A11 and CYP4F2 enzymes catalyze $\omega$-hydroxylation of arachidonic acid to produce the eicosanoid, 20-HETE (Lasker et al. 2000). CYP4A11 also metabolizes lauric acid, while CYP4F2 metabolize arachidonic acid, but not lauric acid (Lasker et al. 2000). The role of other CYP4 members such as CYP4F3A, CYP4F3B and CYP4F11 are unclear although these CYPs also produce 20-HETE from arachidonic acid. Of interest, CYP4F2 and CYP4F3B inactivate the potent inflammatory agent leukotriene $\mathrm{B} 4$, suggesting their involvement in fatty acid homeostasis and/or tissue inflammation (Johnson et al. 2015). Mechanistic studies suggest that 20-HETE has anti-hypertensive effects in the PT, where it activates protein kinase $\mathrm{C}$ that phosphorylates Na-K-ATPase, leading to a reduction in sodium transport activity (Fan et al. 2015). In the thick ascending limb of the loop of Henle (TALH), 20-HETE has a natriuretic effect because it inhibits $\mathrm{Na}^{+}-\mathrm{K}^{+}-2 \mathrm{Cl}^{-}$and $70 \mathrm{pS}$ $\mathrm{K}^{+}$transport, causing a reduction in reabsorption of sodium (Fan et al. 2015). In vascular smooth muscle cells, 20-HETE is a local vasoconstrictor and thus is pro-hyper- 
tensive (Wu et al. 2014a). Role for 20-HETE in pathogenesis of hypertension can be deduced from studies, detailed below.

Laffer et al. (2003a) examined the change in urinary 20-HETE excretion following salt loading and depletion in salt-resistant hypertensive and salt-sensitive hypertensive subjects and found urinary excretion of 20-HETE levels were increased in both groups following saline loading. A correlation between elevated urinary 20-HETE excretion and increased sodium excretion was seen only in salt-resistant hypertensive patients. Laffer et al. (2003a) suggested that a lack of inhibition of sodium transport by 20-HETE might contribute to an increase in blood pressure in saltsensitive patients following salt loading. In an Australian study, a positive correlation between urinary 20-HETE and blood pressure was seen, and hypertensive women had greater urinary 20-HETE levels than normotensive subjects (Ward et al. 2004). In addition, urinary 20-HETE correlated with F2-isoprostanes (a lipid peroxidation product) and serum GGT, suggesting oxidative stress and inflammation in subjects with elevated urinary 20-HETE excretion or high activity of CYP-mediated $\omega$-hydroxylation of arachidonic acid (Ward et al. 2005). In another study, an expected increase in urinary 20-HETE excretion following administration of furosemide (a diuretic drug) was found in normal subjects, but not in salt-sensitive hypertensive subjects. Laffer et al. (2003b) concluded that impaired synthesis or actions of renal 20-HETE might contribute to the salt-sensitive hypertension.

\section{Cadmium and the pathogenesis of hypertension in humans}

Previously, effects of $\mathrm{Cd}$ exposure on CYP protein abundance have been examined in post-mortem Australian liver and kidney samples with known elevated Cd levels (Baker et al. 2002, 2003, 2005). In one study (Baker et al. 2005), kidney Cd accumulation levels, ranging between 2 and $63 \mu \mathrm{g} / \mathrm{g}$ kidney cortex wet weight correlated with CYP4F2 protein levels $(r=0.44, p=0.01)$ and age of donor $(r=0.41, p=0.02)$. Controlling for age did not affect the strength of correlation between kidney $\mathrm{Cd}$ content and CYP4F2 levels. In two other studies (Baker et al. 2002, 2003), kidney cortex CYP4A11 protein levels showed an inverse correlation with kidney cortex $\mathrm{Cd}$ levels; low CYP4A11 protein levels were detected in the kidney cortex samples with high Cd levels of up to $60 \mu \mathrm{g} / \mathrm{g}$ kidney wet weight). Effects of 24-hr (acute) and 13-day (chronic) $\mathrm{Cd}$ exposure on transcript levels of the various genes in cultured human PTCs have been demonstrated using the Human Genome GeneChip U133 Plus 2.0 arrays (Affymetrix), probing for more than 47,000 human transcripts and variants representing approximately 39,000 of human gene transcripts and expressed sequence tags (Garrett et al. 2011). The U133 GeneChip results show that $\mathrm{Cd}$ differentially affects expression levels of a large number of genes in cultured human PTCs, including CYP enzymes (CYP2E1, CYP4F3, CYP4F11) together with HO-1 and interleukin-8 (IL-8), a pro-inflammatory cytokine. Induction of these three CYP forms, HO-1, and IL-8 are seen in both acute (1-day) and chronic (13-day) exposure conditions. Supporting the U133 GeneChip data, Li et al. (2013) observed that expression of IL-6, and IL-8 in human primary renal proximal tubular cells were increased after $\mathrm{Cd}$ exposure. Only a few previous studies have examined CYP expression in primary culture of human proximal tubular cells (PTCs). In our recent work, we have observed CYP3A4, CYP2E1, CYP4F2 and MT proteins, but not CYP4A11, CYP2B6 or HO-1 protein, in primary human PTCs, unexposed to Cd (Boonprasert et al. 2016). HO-1 protein levels in those primary human PTCs used in our study were increased to detectable levels $48 \mathrm{hrs}$ after exposure to $5 \mu \mathrm{M} \mathrm{Cd}$, while a further increase in MT protein levels was detected $48 \mathrm{hrs}$ after exposure to $\mathrm{Cd}$ at $0.5 \mu \mathrm{M}$, 10 times lower than the $5 \mu \mathrm{M}$ level required to increase HO-1 expression to detectable levels (Boonprasert et al. 2016). However, no inductive effects of $\mathrm{Cd}$ were evident for CYP2E1, CY3A4 or CYP4F2. Discrepancies in $\mathrm{Cd}$ effects on CYP2E1 induction may be due to differences in PTCs used, experimental conditions and sensitivity of protein vs. transcript determination assays. Collectively, there is evidence to substantiate potential effects of $\mathrm{Cd}$ exposure on human renal CYP expression.

Fig. 2 is a schematic diagram showing pathogenesis of hypertension after decades of dietary $\mathrm{Cd}$ intake, consistent with data from our research and from the literature reports. Cd from foodstuffs (diet) is absorbed and delivered to liver via portal blood circulation. Subsequently, $\mathrm{Cd}$ is released from the liver into bile and systemic blood circulation, mostly in protein-bound complex forms (Cd-MT). By virtue of its small molecular weight, Cd-MT complexes pass through the glomeruli into the glomerular filtrate and are reabsorbed by PTCs and are subjected to degradation. Presumably, degradation of Cd-MT complexes results in a release of unbound or free $\mathrm{Cd}^{2+}$ ions, causing oxidative stress and depletion of endogenous anti-oxidants such as glutathione and bilirubin (Nair et al. 2015). Cd-induced oxidative stress produces damage to a variety of proteins in tubular epithelial cells, notably the Na/K-ATPase (Thevenod and Friedmann 1999). The oxidized $\mathrm{Na} /$ $\mathrm{K}$-ATPase is degraded by the proteasome and endo-lysosomal protease, causing a fall in cellular concentrations and sodium transport activity of the $\mathrm{Na} / \mathrm{K}$-ATPase. In cortical proximal tubular cells, high $\mathrm{Cd}$ accumulation levels increase expression levels CYP4F2, and CYP4F11 with more 20-HETE being produced (Baker et al. 2005; Garret et al. 2011). However, because of low abundance of $\mathrm{Na} /$ K-ATPase as an outcome of $\mathrm{Cd}$ toxicity, the ability for 20-HETE to inhibit salt re-absorption is impaired. Low CYP4A11 protein expression in the DT in those with high $\mathrm{Cd}$ body burden, as suggested by an inverse correlation between kidney Cd levels and CYP4A11 protein abundance (Baker et al. 2003) suggests that only low-level 20-HETE production in this nephron portion, where 20-HETE reduces 


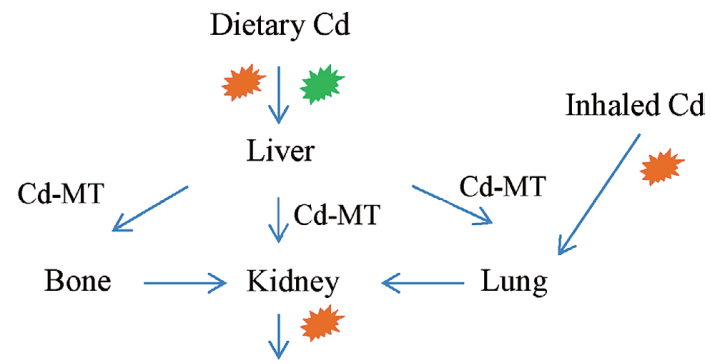

Oxidative stress \& Inflammation

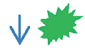

Oxidized Na/K-ATPase, CYP4F $\uparrow$ in PT, CYP4A11 $\downarrow$ in DT

$\downarrow$

Proteolysis $\uparrow$

$\downarrow$

Altered $\omega$-hydroxylation of AA

$\downarrow$

$\mathrm{Na} / \mathrm{K}$-ATPase $\downarrow \downarrow \quad 20$-HETE $\uparrow$ in PT, 20-HETE $\downarrow$ in DT

$\downarrow$

Salt and water retention $\uparrow$

$\downarrow$

Plasma volume $\uparrow$

$\vee$

Pressure-natriuresis response reset

$\downarrow$

Persistently high blood pressure

Fig. 2. Pathogenesis of hypertension in chronic cadmium exposure and modulation by plant antioxidants.

The symbol denotes modulation by essential elements such as zinc, iron and calcium. The symbol denotes modulation by plant antioxidants. By virtue of small molecular weight, Cd-MT complexes pass through glomerular membrane, and are internalized into proximal tubular cells, in which cells they are degraded with resultant release of toxic free $\mathrm{Cd}^{2+}$ ions, causing damage to $\mathrm{Na} / \mathrm{K}$-ATPase and a fall in its salt transport activity. CYP4F2 and CYP4F11 expression in cortical proximal tubule cells (PT) are increased by higher $\mathrm{Cd}$ levels that are re-absorbed, but CYP4A11 expression in distal tubules (DT) is diminished by lower Cd levels reabsorbed from the filtrate, compared with PT. In DT, low levels of 20-HETE are produced, leading to a greater re-uptake of salt and water into systemic circulation. Hypertension develops after prolonged volume overload, increasing sodium retention and a shift of natriuretic response to higher pressures. $\mathrm{AA}=$ Arachidonic acid; Cd-MT $=$ Cd bound to metallothionein; 20-HETE = 20-hydroxyeicosatetraenoic acid.

sodium reabsorption through inhibition of $\mathrm{Na}^{+}-\mathrm{K}^{+}-2 \mathrm{Cl}^{-}$and $70 \mathrm{pS} \mathrm{K}^{+}$transport. Low 20-HETE levels in the DT, thus, lead to a greater re-uptake of salt and water into systemic circulation. Hypertension develops after prolonged volume overload, increasing sodium retention and shifting the natriuretic response to higher pressures.

\section{Cadmium exposure and mortality}

Table 2 provides a summary of longitudinal observations of $\mathrm{Cd}$ toxicity outcomes. In a 26-year follow-up of 7,529 residents in an area with Cd pollution, Maruzeni et al. (2014) found increases in death among men and women with high $\mathrm{Cd}$ exposure and signs of kidney effects (proteinuria and glycosuria) at baseline assessment between 1979 and 1984, with greater risks in women than men (female HR $2.40,95 \%$ CI $2.16-2.80$ vs. male HR $1.57,95 \%$ CI 1.29-1.90). Increased risk of death from ischemic heart disease, and increased incidence of diabetes and renal disease were seen in both men and women with signs of kidney effects, but excess risk of cancer of kidney, urinary tract, uterus, colon and rectum were seen in women only. More severe outcomes of $\mathrm{Cd}$ exposure in women than men have been noted in a previous report (Nishijo et al. 2004). Increased risk of death among people showing signs of $\mathrm{Cd}$ kidney toxicity could be interpreted to suggest that that such kidney Cd toxicity may be an early warning of complications, sub-clinical or clinical morbidity.

In a follow-up of the U.S. NHANES 1999-2004 participants (median 5.8, 2.8 follow-up yrs), Patel et al. (2013) found a 1-SD change in logged exposure levels was associated with death from all causes (HR 1.6, 95\% CI 1.3, 2.0 for urinary $\mathrm{Cd}$, and $\mathrm{HR} 1.4,95 \%$ CI 1.2, 1.6 for blood $\mathrm{Cd}$ ). Other factors found to be associated with death along with $\mathrm{Cd}$ exposure are physical inactivity, smoking, and low serum lycopene (most likely reflect low-level dietary intake of vegetable antioxidants). In a follow-up of NHANES III (1988-1994) participants, Adams et al. (2012) found increases in death from lung cancer among men who had urinary $\mathrm{Cd} \geq 0.58 \mu \mathrm{g} / \mathrm{g}$ creatinine (HR 3.22, 95\% CI 1.268.25), while Hyder et al. (2013) found increases in death from non-malignant, liver-related diseases among women with urinary $\mathrm{Cd} \geq 0.83 \mu \mathrm{g} / \mathrm{g}$ creatinine and men with urinary $\mathrm{Cd} \geq 0.65 \mu \mathrm{g} / \mathrm{g}$ creatinine (HR 3.42, 95\% CI 1.1210.47). Consistent with the Japanese findings, Tellez-Plaza et al. (2012) found increases in death from cardiovascular disease (CVD) (HR 1.74, 95\% CI 1.07-2.83), from ischemic heart disease (HR 2.53 95\% CI 1.54-4.16), and from coronary heart disease (HR 2.09, 95\%, 1.06-4.13) among those with urinary $\mathrm{Cd} \geq 0.57$ vs. $0.14 \mu \mathrm{g} / \mathrm{g}$ creatinine. Population attributed risks predict that a $25 \%$ reduction in $\mathrm{Cd}$ exposure (a fall of urinary $\mathrm{Cd}$ from 0.57 to $0.14 \mu \mathrm{g} / \mathrm{g}$ creatinine) will prevent $8.8 \%$ overall deaths and $9.2 \%$ from $\mathrm{CVD}$ deaths. An equivalent risk analysis of $\mathrm{Cd}$ exposure using blood $\mathrm{Cd}$ as an exposure biomarker gives parallel results: a reduction of blood Cd from 0.80 to $0.22 \mu \mathrm{g} / \mathrm{L}$ will prevent death from all causes and from CVD by $7 \%$ and $7.5 \%$, respectively. Lifetime $\mathrm{Cd}$ exposure and heart disease onset have been evidenced from a 17-year follow-up of 4,378 Swedish men and women, aged 46-67 yrs, who had no history of either heart failure or atrial fibrillation (Borne et al. 2015). Mean (range) of blood Cd in the Swedish sample group was 0.24 (range; 0.02-5.07) $\mu \mathrm{g} / \mathrm{L}$ in men and the corresponding value in women was $0.27(0.03-4.8) \mu \mathrm{g} /$ 
Table 2. Cadmium exposure and death from all causes, cancer and Alzheimer's disease.

\begin{tabular}{|c|c|}
\hline Population/Study synopsis & Risk estimates \\
\hline $\begin{array}{l}\text { A 26-year follow-up of } n 7529 \text { in an area } \\
\text { polluted by Cd, and } n 2149 \text { in a control } \\
\text { area, with urinary Cd levels, and kidney } \\
\text { toxicities measured at baseline. }\end{array}$ & $\begin{array}{l}\text { Kidney Cd toxicity }{ }^{\text {a }} \text { was implicated in deaths in men (HR } 1.57 \text {, } \\
95 \% \text { CI } 1.29-1.90 \text { ) and women (HR 2.40, } 95 \% \text { CI } 2.16-2.80 \text { ). } \\
\text { In both men and women, kidney Cd toxicities were implicated in } \\
\text { deaths from ischemic heart disease, diabetes and renal disease. } \\
\text { In women only, kidney Cd toxicities were implicated in deaths } \\
\text { from cancer of various sites (kidney, urinary tract, uterus, colon } \\
\text { and rectum). }\end{array}$ \\
\hline $\begin{array}{l}\text { Sweden, low-level exposure, Borne et al. } \\
(2015) \text {. } \\
\text { A 17-year follow-up of } n 4378 \text { ( } 60 \% \\
\text { women) in the Malmo Diet and Cancer } \\
\text { study, aged } 46-67 \text { yrs, with no history of } \\
\text { heart failure. }\end{array}$ & $\begin{array}{l}\text { In both men and women, blood Cd levels in the highest quartile } \\
(0.49-5.07 \mu \mathrm{g} / \mathrm{L} \text { in men and } 0.49-4.83 \mu \mathrm{g} / \mathrm{L} \text { in women) were } \\
\text { associated with increased incidence of heart failure (age-adjusted } \\
\text { HR } 2.64,95 \% \text { CI } 1.60-4.36) \\
\text { In men, mean (range) of blood Cd levels were } 0.24(0.02-5.07) \\
\mu \mathrm{g} / \mathrm{L} \text {. In women, mean (range) of blood Cd levels were } 0.27 \\
(0.03-4.83) \mu \mathrm{g} / \mathrm{L} \text {. }\end{array}$ \\
\hline $\begin{array}{l}\text { Median 2.5-5.8-year follow-up of } \\
n 22076 \text { in NHANES 1999-2000, 2001- } \\
02,2003-04 .\end{array}$ & $\begin{array}{l}\text { A 1-SD change in logged }{ }^{b} \text { urinary Cd levels was associated with } \\
\text { mortality (HR } 1.6,95 \% \text { CI } 1.3-2.0) \text {. } \\
\text { A 1-SD change in logged blood Cd levels was associated with } \\
\text { mortality (HR 1.4, 95\% CI 1.2-1.6). } \\
\text { In addition to Cd exposure, inactivity, smoking, and low serum } \\
\text { lycopene contribute to death from all causes. }\end{array}$ \\
\hline $\begin{array}{l}\text { U.S., Tellez-Plaza et al. (2012) } \\
\text { Average 4.8-year follow-up of } n 8989 \\
\text { participants in NHANES 1999-2004. }\end{array}$ & $\begin{array}{l}\text { Urinary Cd levels increase from } 0.14 \text { to } 0.57 \mu \mathrm{g} / \mathrm{g} \text { creatinine is } \\
\text { associated with death from CVD (HR } 1.74,95 \% \text { CI } 1.07-2.83 \text { ), } \\
\text { ischemic heart disease (HR } 2.53,95 \% \text { CI } 1.54-4.16 \text { ) and } \\
\text { coronary heart disease (HR } 2.09,95 \%, 1.06-4.13 \text { ). } \\
\text { Reducing urinary Cd } \geq 0.57 \mu \mathrm{g} / \mathrm{g} \text { creatinine to } 0.14 \mu \mathrm{g} / \mathrm{g} \\
\text { creatinine could have had prevented } 8.8 \% \text { of overall deaths and } \\
9.2 \% \text { of deaths from CVD. }\end{array}$ \\
\hline $\begin{array}{l}\text { U.S., Adams et al. (2012) } \\
\text { Average 13.4-year follow-up of } n 7455 \\
\text { men and } n 8218 \text { women in NHANES III } \\
(1988-1994) \text {. }\end{array}$ & $\begin{array}{l}\text { A 2-fold increase in urinary Cd levels was associated death from } \\
\text { cancer in both men and women (male HR } 1.26,95 \% \text { CI } 1.07 \text { - } \\
1.48 \text {; female HR } 1.2195 \% \text { CI } 1.04-1.42 \text { ). } \\
\text { Urinary Cd levels } \geq 0.58 \mu \mathrm{g} / \mathrm{g} \text { creatinine were associated with } \\
\text { lung cancer in men (HR 3.22, 95\% CI 1.26-8.25). }\end{array}$ \\
\hline $\begin{array}{l}\text { U.S., Lin et al. (2013) } \\
\text { A 12.4-yr follow-up of } n 5204, \text { NHANES } \\
\text { III (1988-1994). }\end{array}$ & $\begin{array}{l}\text { Urinary Cd levels }>0.79 \mu \mathrm{g} / \mathrm{g} \text { creatinine were associated with } \\
\text { cancer death in men (HR } 3.13,95 \% \text { CI } 1.88-5.20) \text {. Urinary Cd } \\
\text { levels }>1.05 \mu \mathrm{g} / \mathrm{g} \text { creatinine were associated with cancer deaths } \\
\text { in women (HR } 1.65,95 \% \text { CI } 1.13-2.41) \text {. }\end{array}$ \\
\hline $\begin{array}{l}\text { U.S., Hyder et al. (2013) } \\
\text { Median 14.6-year follow-up of } n 12732 \text {, } \\
\text { NHANES III (1988-1994). }\end{array}$ & $\begin{array}{l}\text { Male urinary Cd levels } \geq 0.65 \mu \mathrm{g} / \mathrm{g} \text { creatinine and female urinary } \\
\text { Cd levels } \geq 0.83 \mu \mathrm{g} / \mathrm{g} \text { creatinine were associated with deaths } \\
\text { from non-malignant, liver-related disease (HR } 3.42,95 \% \mathrm{CI} \\
1.12-10.47 \text { ). }\end{array}$ \\
\hline $\begin{array}{l}\text { U.S., Min and Min (2016) } \\
\text { A followed-up of } n 4060 \text {, aged } \geq 60 \text { yrs, } \\
\text { NHANES }(1999-2004) \text {. }\end{array}$ & $\begin{array}{l}\text { Blood Cd levels }>0.6 \mu \mathrm{g} / \mathrm{L} \text { were associated with death from } \\
\text { Alzheimer's disease (HR 3.83, 95\% CI 1.39-10.59), compared } \\
\text { with blood Cd levels }<0.3 \mu \mathrm{g} / \mathrm{L} \text {. }\end{array}$ \\
\hline
\end{tabular}

aProteinuria and glycosuria. ${ }^{b}$ Logarithmic transformation.

CVD, Cardiovascular disease; NHANES, National Health and Nutrition Examination Survey; $n$, sample size; CI, Confidence interval; HR, Hazard ratio.

L. An increase in risk of heart failure was seen among those with blood levels in the $4^{\text {th }}$ quartile (HR $1.95,95 \%$ CI 1.02-3.71) after adjustment for age and conventional risk factors and biomarkers. In a follow-up of 4,060 participants in the NHANES 1999-2004 (Min and Min 2016), blood Cd levels $>0.6 \mu \mathrm{g} / \mathrm{L}$ were associated with death from Alzheimer's disease (HR 3.83, 95\% CI 1.39-10.59).

\section{Cadmium -Mechanisms of toxicity}

Table 3 provides a summary of studies that quantify oxidative stress and inflammation in relationship to $\mathrm{Cd}$ exposure. In the NHANES III (1988-1994) data, Hyder et al. (2013) found liver inflammation in women was associated with urinary $\mathrm{Cd}>0.83 \mu \mathrm{g} / \mathrm{g}$ creatinine, while NAFLD and NASH in men were associated with urinary $\mathrm{Cd}>0.65$ $\mu \mathrm{g} / \mathrm{g}$ creatinine. Lee et al. (2006) also analysed data from adult participants of NHANES III, and they found increased urinary $\mathrm{Cd}$ levels were associated with increased serum GGT levels, while increased blood Cd levels were associated with increased serum ALP levels, prevalence of diabe- 
Table 3. Cadmium exposure, oxidative stress and systemic inflammation.

\begin{tabular}{|c|c|}
\hline Study synopsis & Findings \\
\hline $\begin{array}{l}\text { Cd exposure and risk of liver inflammation, } \\
\text { NAFLD, and NASH, Hyder et al. (2013) } \\
\text { NHANES III, } n 12732 \text {, aged } \geq 20 \text { yrs. }\end{array}$ & $\begin{array}{l}\text { In women, urinary Cd levels } \geq 0.83 \mu \mathrm{g} / \mathrm{g} \text { creatinine were } \\
\text { associated with liver inflammation (OR } 1.26,95 \% \text { CI } 1.01 \text { - } \\
1.57 \text { ) } \\
\text { In men, urinary Cd levels } \geq 0.65 \mu \mathrm{g} / \mathrm{g} \text { creatinine were } \\
\text { associated with liver inflammation (OR } 2.21,95 \% \text { CI } 1.64-3 \text {, } \\
\text { NAFLD (OR } 1.30,95 \% \text { CI } 1.01-1.68 \text { ) and NASH (OR } 1.95 \text {; } \\
\text { 95\% CI } 1.11-3.41 \text { ). }\end{array}$ \\
\hline $\begin{array}{l}\text { Serum GGT, vitamins C \& E, and } \\
\text { carotenoids in relationship to urinary Cd } \\
\text { levels, Lee et al. (2006), NHANES III, } \\
n 10098, \text { aged } \geq 20 \mathrm{yrs} .\end{array}$ & $\begin{array}{l}\text { Serum GGT levels show a positive association with urinary } \\
\text { Cd levels ( } 0.002 \text { to } 23.4 \mu \mathrm{g} / \mathrm{g} \text { creatinine (mean } 0.37 \mu \mathrm{g} / \mathrm{g} \\
\text { creatinine), but serum levels of vitamin C, carotenoids, and } \\
\text { vitamin E show an inverse association. }\end{array}$ \\
\hline $\begin{array}{l}\text { Serum CRP and fibrinogen in relationship to } \\
\text { urinary Cd levels, Lin et al. (2009), } \\
\text { NHANES III, } n 6497 \text {, aged } 40-79 \text { yrs. }\end{array}$ & $\begin{array}{l}\text { An approximate } 3 \text {-fold increase in urinary } \mathrm{Cd} \text { (from } \leq 0.3 \text { to } \\
\geq 0.93 \mu \mathrm{g} / \mathrm{g} \text { creatinine) is associated with an abnormal serum } \\
\text { levels of CRP (OR 1.24), and of fibrinogen (OR 2.12) }\end{array}$ \\
\hline $\begin{array}{l}\text { Length of leucocyte telomeres in } \\
\text { relationship to blood and urinary Cd \& Pb } \\
\text { levels, Zota et al. (2014), NHANES 1999- } \\
\text { 2002, } n 6796 \text { with blood Pb and Cd } \\
\text { measured, } n 2093 \text { with urinary Cd and } \\
\text { leucocyte telomere lengths measured. }\end{array}$ & $\begin{array}{l}\text { Dose-response between telomere lengths and Cd exposure } \\
\text { levels; two-fold increment in urinary } \mathrm{Cd} \text { and blood } \mathrm{Cd} \text { are } \\
\text { associated with } 1.10 \% \text {, and } 2.46 \% \text { shorter telomeres } \\
\text { respectively. } \\
\text { No association between blood } \mathrm{Pb} \text { levels and leucocytes } \\
\text { telomere length. }\end{array}$ \\
\hline $\begin{array}{l}\text { Leucocyte telomere length in relationships } \\
\text { to } 461 \text { indicators of environmental } \\
\text { exposures, physiology and self-reported } \\
\text { behaviour, Patel et al. (2016), NHANES } \\
\text { 1999-2002 participants. }\end{array}$ & $\begin{array}{l}\text { Shorter leucocyte telomere lengths were associated with } \mathrm{Cd} \\
\text { exposure along with seven other factors, including serum } \\
\text { CRP, trunk fat, and physical inactivity. } \\
\text { Longer leucocyte telomere lengths were associated with } \\
\text { serum levels of retinyl stearate (a form of vitamin A). }\end{array}$ \\
\hline
\end{tabular}

\begin{tabular}{ll}
\hline Serum bilirubin in relationships to Cd & Reduction in serum bilirubin by $4.9 \%$ (ranging from $1.55 \%$ to \\
exposure levels, Pollack et al. (2015), $n 259$ & $8.17 \%$ ) was associated with a two-fold increase in blood Cd \\
healthy women (aged 18-44 yrs) in Buffalo, & levels. \\
New York. &
\end{tabular}
New York.

Median (interquartile range) Cd levels were 0.3 (0.19-0.43) $\mu \mathrm{g} / \mathrm{L}$.

\begin{tabular}{ll}
\hline $\begin{array}{l}\text { Serum levels of CRP, GGT, ALP, bilirubin } \\
\text { and white cell counts in relationships to } \\
\text { urinary Cd and scores for dietary intake of } \\
\text { vitamins A, B6, C, and E, } \alpha \text {-and } \beta \text {-carotene, }\end{array}$ & $\begin{array}{l}\text { Increases in serum CRP (47.5\%), GGT (8.8\%) and ALP } \\
(3.7 \%) \text { were associated with an interquartile urinary Cd }\end{array}$ \\
$\begin{array}{l}\beta \text {-cryptoxanthin, lycopene, lutein, } \\
\text { zeaxanthin, Se, Mg, Zn, Cu, Fe, fat }\end{array}$ & $\begin{array}{l}\text { A } 3.0 \% \text { increase in serum bilirubin and respective reduction } \\
\text { in CRP, GGT, ALP, and white blood cell counts by } 7.4 \%,\end{array}$ \\
$\begin{array}{ll}\text { (unsaturated), and fiber, Colancino et al. } \\
\text { (2014), NHANES 2003-2010, } n 3056\end{array}$ & $\begin{array}{l}3.3 \%, 5.2 \% \text {, and } 2.5 \% \text { were associated with high dietary } \\
\text { intake of anti-oxidative and anti-inflammatory nutrients. }\end{array}$ \\
women, $n 3288$ men. &
\end{tabular}

NAFLD, Non-alcoholic fatty liver disease; NASH, Non-alcoholic steatohepatitis; $n$, sample size; CI, Confidence interval; OR, Odds ratio; GGT, $\gamma$-Glutamyl transferase; CRP, C-reactive protein; ALP, Alkaline phosphatase.

tes and hypercholesterolemia. In another study of NHANES III (1988-1994) participants, aged 40-79 years, high serum levels of CRP and fibrinogens were associated with urinary Cd levels in a dose-dependent manner (Lin et al. 2009). In NHANES 1999-2004, blood Cd levels among men $\geq 40$ years of age rose with increasing serum ALP levels (Cheung et al. 2009). Three separate analyses of the U.S. population data (Lee et al. 2006; Cheung et al. 2009; Lin et al. 2009) have implicate $\mathrm{Cd}$ exposure as a risk factor in subclinical liver inflammation.

In NHANES 1999-2002 data, Zota et al. (2015) found the length of leucocyte telomeres $1.10 \%$, and $2.46 \%$ shorter per doubling of urinary $\mathrm{Cd}$ and blood $\mathrm{Cd}$, respectively, and they suggested that $\mathrm{Cd}$ may cause oxidative stress, given telomeres are high sensitivity to damage by oxidative stress, due to the high GC content in telomeres. In a separate analysis of the same NHANES 1999-2000 dataset, Patel et al. (2013) found an association of Cd exposure and shortening of leucocyte telomeres, similar to the report of Zota et al. (2015). In addition to $\mathrm{Cd}$ exposure, leukocyte telomere lengths showed an inverse association with serum CRP levels, physical activity, and trunk fat (Patel et al. 2016). 
These associations of short telomeres and $\mathrm{Cd}$ exposure, trunk fat and CRP suggest chronic inflammation due to $\mathrm{Cd}$ and/or obesity (high trunk fat). Pollack et al. (2015) investigated a change in serum bilirubin levels in relationship to Cd exposure levels in 259 women, aged 18-44 yrs, and they found that doubling of blood $\mathrm{Cd}$ levels was associated with a fall in serum bilirubin levels by $4.9 \%$. Colancino et al. (2014) have quantified oxidative stress and inflammation among NHANES 2003-2010 participants, and they found high urinary $\mathrm{Cd}$ associated with increased serum levels of CRP (47.5\%), GGT (8.8\%), and ALP (3.7\%). In addition, Colancino et al. (2014) have found diet with high composite scores of antioxidant and anti-inflammatory nutrients associated with a $3.0 \%$ increase in serum bilirubin along with a $7.4 \%, 3.3 \%, 5.2 \%$, and $2.5 \%$ reduction in CRP, GGT, ALP, and total white blood cell counts, respectively. Collectively, these data suggest elevated oxidative stress and systemic inflammation among those with high $\mathrm{Cd}$ exposure levels that could possibly be offset by a diet rich in antioxidants and anti-inflammatory nutrients. An analysis of the dietary intake revealed vitamins A, B6, C, and E, $\alpha$-and $\beta$-carotene, $\beta$-cryptoxanthin, lycopene, lutein, zeaxanthin, $\mathrm{Se}, \mathrm{Mg}, \mathrm{Zn}, \mathrm{Cu}, \mathrm{Fe}$, fat (unsaturated), and fibre.

\section{Cadmium -Reduction of exposure and mitigation of toxicity outcomes}

Dietary Cd exposure levels, experienced by the current population worldwide may have reached the levels that adversely affect kidney function in a significant proportion of the general population (Tables 1, 2 and 3). Urinary $\mathrm{Cd}$ levels $\geq 1 \mu \mathrm{g} / \mathrm{L}$ were associated with an increased risk of CKD in participants in the U.S. NHANES 1999-2006 (Ferraro et al. 2010). In this sample group, overall (female) prevalence of urinary $\mathrm{Cd}>1,>0.7$ and $>0.5 \mu \mathrm{g} / \mathrm{g}$ creatinine among non-smokers $(\geq 20 \mathrm{yrs})$ who did not have CKD was 1.7 (2.5), 4.8 (7.1), and 10.8 (16) \%, respectively (Mortensen et al. 2011). Lin et al. (2014) reported the prevalence of diminished kidney function among the NHANES 2011-2012 participants of 7.4\% and blood Cd levels $>0.53$ $\mu \mathrm{g} / \mathrm{L}$ were associated with an increased risk of albuminuria and diminished GFR. This prevalence exceeds the 5\% acceptable disease prevalence in the general population. Likewise, Kim et al. (2015) reported the prevalence of CKD in Korean population of $7.1 \%$, while noting an increase in sensitivity to $\mathrm{Cd}$ toxicity in those with hypertension and/or diabetes. In a Swedish study, blood Cd level as low as $0.34 \mu \mathrm{g} / \mathrm{L}$ was associated with signs of kidney toxicity, especially in diabetic subjects (Barregard et al. 2014). These data call for primary and secondary public measures, as detailed below, to prevent a further rise in the prevalence of CKD and many other chronic illness such as diabetes and hypertension, shown to be associated also with $\mathrm{Cd}$ exposure.

\section{Minimization of food-chain transfer}

Total diet study shows staple foods such as rice, pota- toes, and wheat account for $40-60 \%$ of total dietary $\mathrm{Cd}$ intakes by average consumers. Diets high in shellfish, crustaceans, molluscs, spinach, and offal add to dietary $\mathrm{Cd}$ sources. Minimization of $\mathrm{Cd}$ levels in food crops is an effective public measure to reduce dietary $\mathrm{Cd}$ exposure levels and adverse health effects, notably vascular complications of diabetes worldwide. Work in 1960s recognized phosphate fertilizers as a potential cause of dietary $\mathrm{Cd}$ exposure, given the high $\mathrm{Cd}$ levels in some vegetables grown on soils heavily fertilized with phosphate fertilisers (Schroeder and Balassa 1963). Soils with Cd exceeding 3 $\mathrm{mg} / \mathrm{kg}$ environmental safety limit should be prohibited for use in production of food crops for consumption (reviewed in Satarug et al. 2003). Risk reduction measures such as the MPC for Cd in various food crops, supported by international legislation, should not be relaxed. Such MPC values for $\mathrm{Cd}$ in food crops should be set as low as reasonably achievable through long-term environmental and agricultural management. In a Vietnamese study (Minh et al. 2012), an approximate of $93-95 \%$ of dietary Cd intake was derived from rice, while another $2.4-4 \%$ was from water spinach. In one village, dietary $\mathrm{Cd}$ intake estimates for women (men) were 29 (33) $\mu \mathrm{g} /$ day, given $426 \mathrm{~g}$ of cooked rice consumed per day and a mean (range) rice $\mathrm{Cd}$ content of $0.076(0.030-0.16) \mathrm{mg} / \mathrm{kg}$ dry rice grain weight. In another village, dietary $\mathrm{Cd}$ intake estimates for women (men) were 109 (122) $\mu \mathrm{g} /$ day, given $461 \mathrm{~g}$ of cooked rice was consumed per day and mean (range) rice $\mathrm{Cd}$ content of $0.31(0.034-0.83) \mathrm{mg} / \mathrm{kg}$ dry rice grain weight.

The current MPC for rice, however, is set at $0.4 \mathrm{mg} / \mathrm{kg}$ dry grain weight, but studies in Japan (Osawa et al. 2001) and Vietnam (Minh et al. 2012) have suggested 0.05 to 0.2 $\mathrm{mg} / \mathrm{kg}$ are necessary to provide protection against $\mathrm{Cd}$ toxicity in those who consume on average $400 \mathrm{gm}$ of cooked rice per day, to meet the majority of energy (calorie) requirement. This is a typical Asian diet, which contributes to higher average body $\mathrm{Cd}$ burden in most Asian populations, compared with Caucasian populations, who obtain significant proportion of calories from fat in additional from staples. Persistence of $\mathrm{Cd}$ in the environment, coupled with its high soil-to-plant transfer rates, requires long-term management of $\mathrm{Cd}$ in the environment (soil, air and water), and in agriculture, where consideration should be given to leafy salad vegetables, such as spinach and lettuce, which are known to be hyper-accumulators of Cd. These plants should be strictly grown on soils with low Cd levels, given that diet rich in plant and vegetables provides a rich source of exogenous antioxidants whose protective effects against $\mathrm{Cd}$ toxicity have indeed been observed along with overall mortality risk reduction (Patel et al. 2013; Colancino et al. 2014).

\section{Minimization of gastrointestinal absorption}

$\mathrm{Cd}$ has no known physiologic function, and no mechanisms would have been expected to have evolved for its absorption, transport, and elimination. Most likely, Cd 
absorption and accumulation are mediated by a metal transporter system that the body uses to acquire essential metals such as iron, zinc, and manganese. Because enhanced gastrointestinal absorption of iron is a physiologic response to low body iron store status or iron deficiency, $\mathrm{Cd}$ absorption and body $\mathrm{Cd}$ burden can thus be expected to be heightened in those with iron store depletion and iron deficiency. Higher blood, kidney and urinary $\mathrm{Cd}$ levels have thus been seen frequently in people with low body iron status and iron deficiency, the conditions more prevalent in children and women of reproductive age, compared to men of similar age. This makes women and children to be subpopulations at risk of Cd toxicity. Suh et al. (2016) reported overall prevalence of iron deficiency of $23.1 \%$ in a sample group of 10,169 females (aged $\geq 10$ yrs) in a Korean NHANES 2010-2012. Iron deficiency was more prevalent among adolescents (36.5\%) and women, aged 19-49 yrs (32.7\%). Females with iron deficiency had higher blood Cd levels $(1.53 \mu \mathrm{g} / \mathrm{L})$ than those of similar age and normal iron status $(1.03 \mu \mathrm{g} / \mathrm{L})$. Barregard et al. (2010) found mean Cd levels in kidney biopsies from 109 kidney transplant donors, $24-70 \mathrm{yrs}$ of age (median $51 \mathrm{yrs}$ ) to be $12.9 \mu \mathrm{g} / \mathrm{g}$ wet weight, and they also found women with low iron stores showed elevated kidney Cd levels. Barregard et al. (2010) noted a $15 \%$ increase in kidney $\mathrm{Cd}$ accumulation in nonsmoking Swedish women who had low iron stores, while Olsen et al. (2012) found Swedish women had higher blood Cd than men. Meltzer et al. (2010) noted that non-smoking Norwegian women with low body iron stores had 1.42-fold greater blood $\mathrm{Cd}(0.37 \mu \mathrm{g} / \mathrm{L})$ than similarly aged women with normal body iron stores and that $26 \%$ of those with iron deficiency had high blood Cd levels. Using data from NHANES (2003-2012) participants, Vance and Chun (2015) estimated that a $0.42 \%$ reduction in blood and urinary $\mathrm{Cd}$ is associated with a $10 \%$ increase in dietary zinc intake. Lin et al. (2014) found NHANES (2011-2012) adults with lower zinc status having greater risk of kidney toxicity (OR $3.38,95 \%$ CI, 1.39, 8.28), comparing with those who had higher zinc status. Lin et al. (2013) followed $\geq 50-\mathrm{yr}$ NHANES III participants and they found greater risk of death from cancer among women with zinc intakes below $15 \mathrm{mg} /$ day, the recommended dietary allowance (RDA), compared with women who met the RDA. The association of low zinc intakes and cancer death, observed by Lin et al. (2013), could thus be explained by higher Cd burden among those with low zinc intakes, as noted in the study of Vance and Chun (2015). Taken together these findings suggest minimization of dietary $\mathrm{Cd}$ absorption can be achieved through adequate intake of iron and zinc to meet the body requirement and to maintenance of optimal body status of these essential metals.

Modulation of cadmium toxicity by a stress response mechanism

Heme oxygenase activity and cell survival: $\mathrm{HO}-1$ and $\mathrm{HO}-2$ are two functional isozymes of heme oxygenase that catalyze the degradation of heme to generate ferrous iron, carbon monoxide (CO) and biliverdin IX $\alpha$, which is converted to bilirubin IX $\alpha$ by the enzyme biliverdin reductase (BVR) (Shibahara 2003; Shibahara et al. 2007). A potential role of HO-2 in oxygen-sensing mechanisms (Adachi et al. 2004) and in protection against diabetes and obesity has emerged from studies using the HO-2 knockout mouse model (reviewed in Satarug and Moore 2012). HO-1 and $\mathrm{HO}-2$ both are localized to the endoplasmic reticulum (ER). In addition, HO-1 is found in mitochondria, nucleus and plasma membrane caveolae (Dunn et al. 2014). The presence of HO-1 in the nuclei and mitochondria suggests HO-1 has the functions other than degradation of heme (Dunn et al. 2014). HO-1 expression is controlled by its own substrate (heme) though interaction with Bach1 repressor protein (Igarashi and Watanabe-Matsui 2014). The human HO-1 gene promoter is unique due to the presence of GT repeats of varying lengths (Shibahara et al. 2007). Longer GT repeats (L/L genotype) shows relatively lower basal promoter activity than shorter GT repeats (S/S genotype). Severely damaged proximal tubular cells have been seen in a Japanese HO-1 deficient patient (Ohta et al. 2000). This demonstrates an indispensable role for HO-1 in the survival of the PT cells. Increased HO-1 expression in renal cancer cells promoted their survival and resistance to apoptosis (Banerjee et al. 2012).

Bilirubin and $\mathrm{CO}$ mediate protective effects of $\mathrm{HO}-\mathrm{I}$ induction: Protective effects of HO-1 induction are often attributed to its role in breakdown of pro-oxidant heme and in the generation of bile pigments (biliverdin and bilirubin) and carbon monoxide (CO) (reviewed in Dunn et al. 2014). In an adult human, a total of $400 \mathrm{mg}$ bilirubin is produced per day (Khan and Quigley 2011). HO-1 and HO-2 both contribute to basal serum bilirubin levels. However, because the HO-1 gene is highly inducible by a wide variety of factors that cause stress, it is more likely that elevated serum bilirubin levels are from increased HO-1 expression. In humans, serum bilirubin levels are directly related to the total serum antioxidant capacity and per $1 \mu \mathrm{mol} / \mathrm{L}$ increment in serum bilirubin concentration conferred $14 \%$ and $6.5 \%$ reduction in coronary artery calcification and CVD risk, respectively (Lin et al. 2010). Low serum bilirubin was associated with an increased risk of diabetes among NHANES 1999-2006 participants (Cheriyath et al. 2010) and with an increased risk of coronary artery disease among participants in a statin-treated cohort (Horsfall et al. 2012). Protective effects of bilirubin are related to lipophilic propensities such that bilirubin more effectively protects lipids from oxidation than the water-soluble antioxidants such as glutathione (Durante 2010). Inhibition of low-density lipoprotein oxidation by bilirubin has been suggested as one of biological mechanisms by which higher serum total bilirubin contributes to lowered risk of cardiovascular disease among participants in the PREVEND (Prevention of Renal and Vascular End-stage Disease) prospective study (Kunutsor et al. 2015). 
A role for $\mathrm{CO}$ in mediating effects of HO-1 comes from modeling and preclinical studies, involving administration carbon monoxide-releasing molecules (CORM) (Levitt and Levitt 2015). Exposure to high-dose exogenous $\mathrm{CO}$ has been shown to have anti-inflammatory and antiapoptotic effects, vasodilatation, and heart protection, while exposure to low-dose $\mathrm{CO}$, achievable via endogenous production, resulted in reactive oxygen species (ROS) generation, presumably through inhibition mitochondrial cytochrome C oxidase (COX) by CO (Levitt and Levitt 2015). Elevated ROS production leads to activation of the PI3K/ AKT signaling pathway with subsequent inhibition of glycogen synthase kinase $3 \beta(\mathrm{GSK} 3 \beta)$ and activation of stressactivated nuclear factor erythroid 2-related factor 2 (Nrf2) (Itoh et al. 2015). It is hypothesized that elevation of $\mathrm{CO}$ production through $\mathrm{HO}-1$ induction, p62 and $\mathrm{NAD}(\mathrm{P}) \mathrm{H}$ dehydrogenase quinone 1 (NQO1) are central to biogenesis of mitochondria and the removal of the mitochondria that have been severely damaged (Itoh et al. 2015). Mitochondrial ROS production is a mechanism that cells use to increase their capacity to adapt to stress (Sena and Chandel 2012; Davies 2016).

HO-1 induction by therapeutic drugs and plant antioxidants: HO-1 expression in various types of human cells is induced by a range of therapeutic drugs, such as statins (lipid lowering agent), rosiglitazone (anti-diabetic drug), aspirin (anti-inflammatory drug), paclitaxel and rapamycin (anti-cancer drugs). The therapeutic efficacy of these drugs may be linked, at least in part, to HO-1 induction (reviewed in Dunn et al. 2014). HO-1 expression in human renal cancer cells was induced by anti-renal cancer drugs rapamycin and sorafenib (Banerjee et al. 2012). Intriguingly, a wide range of dietary antioxidants of plant origin such as curcumin, quercetin, tert-butylhydroquinone and caffeic acid phenethyl ester are HO-1 inducers so are catechin (in green tea), $\alpha$-lipoic acid (in broccoli, spinach), resveratrol (in red wine, grapes), carnosol, sulphoraphane (cruciferous vegetable), coffee diterpenes cafestol and kahwoel (reviewed in Durante 2010). Beneficial effects of consumption of these antioxidants could thus be mediated in part through induction of HO-1 expression. In an analysis of NHANES 20032010 data, diet high in anti-oxidative and anti-inflammatory nutrients was associated with a $3.0 \%$ increase in serum bilirubin and reduced oxidative stress and systemic inflammation, suggested by $7.4 \%, 3.3 \%, 5.2 \%$, and $2.5 \%$ reduction in CRP, GGT, ALP, and total white blood cell counts respectively (Colancino et al. 2014). These data suggest that the impact of $\mathrm{Cd}$ exposure can be reduced through consumption of diet rich in antioxidants, and anti-inflammatory nutrients, including vitamins $\mathrm{A}, \mathrm{B} 6, \mathrm{C}$, and $\mathrm{E}, \alpha$-and $\beta$-carotene, $\beta$-cryptoxanthin, lycopene, lutein, zeaxanthin (Colancino et al. 2014).

Human intervention trials have demonstrated the HO-1 inductive propensity of green tea at a usual consumption dose of two cups per day of $150 \mathrm{ml}$ green tea preparation in each cup, containing 1\% (w/v) green tea (Han et al. 2011;
Choi et al. 2015). One of the trials included only diabetic subjects who had no history of metabolic complications, did not smoke or take regular food supplements (Choi et al. 2015). Out of 43 subjects, 23 had long GT repeats (GT repeats $\geq 25 ; \mathrm{L} / \mathrm{L}$ genotype) and 20 had short GT repeats (GT repeats $<25 ; \mathrm{S} / \mathrm{S}$ genotype). The $\mathrm{S} / \mathrm{S}$ group showed higher basal expression of HO-1 protein in lymphocytes, compared with $\mathrm{S} / \mathrm{S}$ group. Based on Western blotting and a comet assay, HO-1 protein levels in circulating lymphocytes were increased by $40 \%$ along with a $50 \%$ increase in protein levels of DNA repair enzyme 8-oxoguanine glycosylase (hOGG1) and reduction in DNA damage by $15 \%$. Green tea consumption appeared to increase HO-1 protein levels in lymphocytes in both $\mathrm{L} / \mathrm{L}$ and $\mathrm{S} / \mathrm{S}$ groups although the $\mathrm{S} / \mathrm{S}$ group showed higher baseline levels of HO-1protein than the $\mathrm{L} / \mathrm{L}$ group. This trial shows a promise of using regular green tea consumption to enhance $\mathrm{HO}-1$ expression to reduce DNA damage that could delay the onset of chronic disease of high prevalence such as diabetes and CKD, known to be associated with increased oxidative stress and inflammation (Small et al. 2012). However, further research is warranted to establish safe and effective bilirubin dose levels because of neurotoxicity potential of high serum bilirubin levels. HO-1 induction by plant antioxidants may as well have anti-obesity and anti-diabetic effects, and thus show promise of use in weight reduction and lowering blood pressure levels.

Dietary $\mathrm{Cd}$ exposure is inevitable for most people and with continuing exposure, tubular injury is likely to arise when cellular protection capacity becomes overwhelming, that is, saturation of metal binding sites of the MT, depletion of endogenous antioxidants such as glutathione, bilirubin (Satarug et al. 2001). Fig. 3 provides a summary of pathway for HO-1 induction by plant antioxidants, listed in section 7.3.3 and molecular targets of Cd toxicity in a hypothetical model of proximal tubular cells. It is suggested that certain plant antioxidants can activate $\mathrm{HO}-1$ expression via the stress response transcription factor, Nrf2 and Stress Responsive Element (StRE), known also as Maf recognition Antioxidant Response Element (MARE). The MARE contains AP-1 binding site and 12-O-tetradecanoylphorbol13-acetate-responsive element. Increased HO-1 expression raises intracellular levels of bilirubin and $\mathrm{CO}$. Bilirubin acts as an endogenously produced antioxidant, while $\mathrm{CO}$ inhibits COX activity with resultant mitochondrial ROS signaling (section 7.3.2). HO-1 induction thus renders PT the capacity to resist toxic effects of $\mathrm{Cd}$ on $\mathrm{Na} / \mathrm{K}$-ATPase, mitochondrial ATP production that ensure cell survival and normal function of transporter system such as SGLUT1, SGLUT2, and NHE3. HO-1 induction by plant antioxidants offer a strategy to protect PT against malfunction, thereby allowing the bulk of nutrients (glucose, amino acids, zinc and calcium) to be returned to systemic circulation for body reutilization and homeostasis. 


\section{Glomerular filtrate}

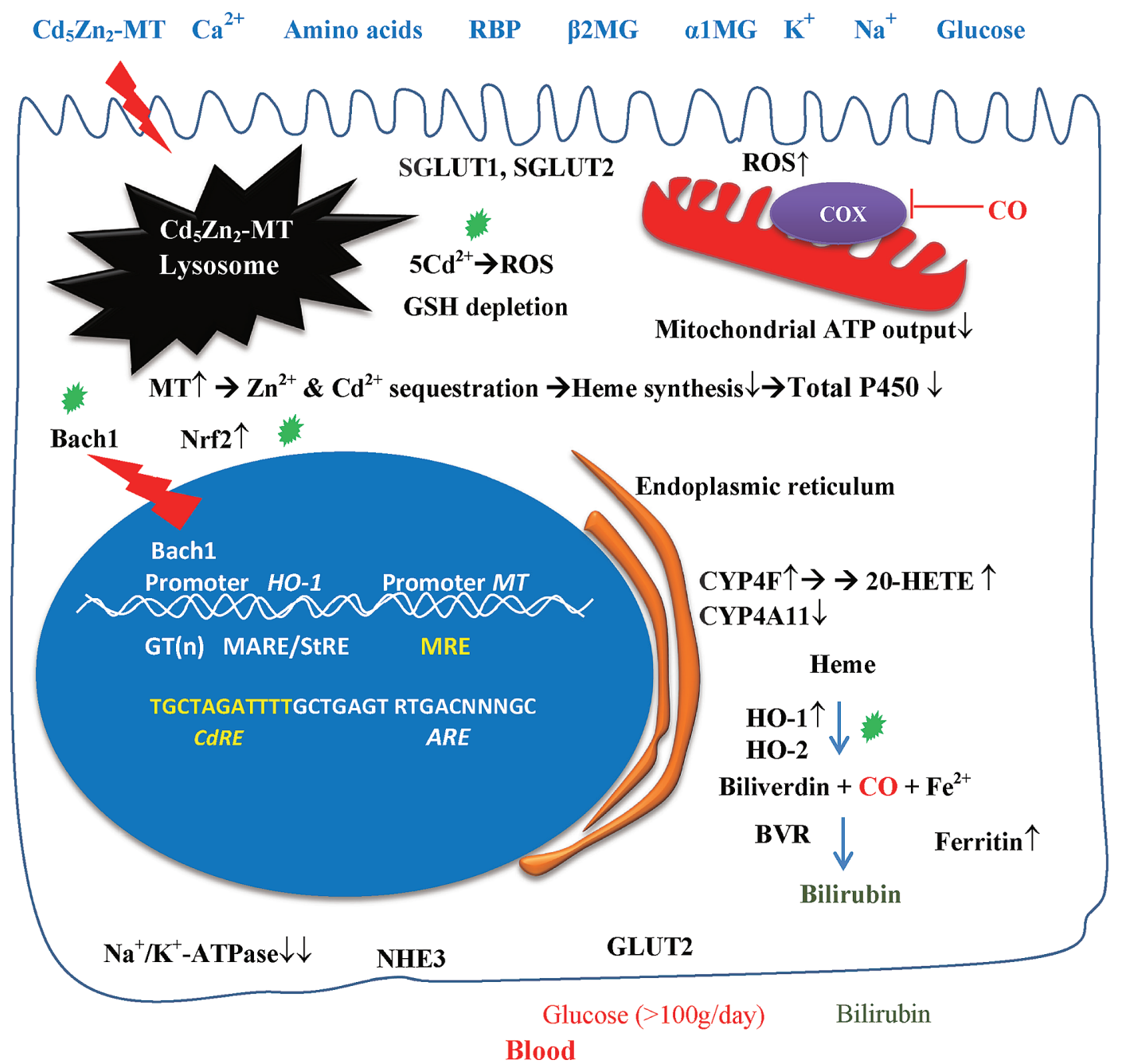

Fig. 3. Activation of a stress response mechanism in a proximal tubular cell model.

The symbol denotes modulation by plant antioxidants. Degradation of $\mathrm{Cd}_{5} \mathrm{Zn}_{2} \mathrm{MT}$ complexes in the proximal tubules (PT) releases $\mathrm{Cd}^{2+}$ ions, which causes GSH depletion. These are signals for activation of the genes, critical for cell survival and detoxification. Newly synthesized metallothionein (MT) proteins sequester $\mathrm{Cd}^{2+}$ ions, thereby preventing an acute toxicity. MT proteins also sequester $\mathrm{Zn}^{2+}$ ions, which reduces availability of $\mathrm{Zn}^{2+}$ ions for normal cell function. Cd-induced heme oxygenase-1 (HO-1) expression is via the CdRE, and MARE, known also as StRE. Cd suppresses the degradation of Nrf2 and causes nuclear export of the repressor Bach1/2, allowing transactivation of the HO-1 gene by the Nrf2/small Maf complex. HO-1 induction elevates levels of bilirubin and $\mathrm{CO}$ that have anti-oxidative, anti-apoptotic propensities, thereby rendering PT the capacity to resist toxic effects of $\mathrm{Cd}$ on $\mathrm{Na} / \mathrm{K}$-ATPase, mitochondria ATP production. In effect, MT and HO-1 induction maintain normal function of transporter system such as SGLUT1, SGLUT2, and NHE3. HO-1 induction by plant antioxidants offer a strategy to protect PT, thereby allowing the bulk of nutrients (glucose, amino acids, zinc and calcium) to be returned to systemic circulation for body reutilization and homeostasis. $\mathrm{ARE}=$ Antioxidant response element; $\mathrm{BVR}=$ Biliverdin reductase; $\mathrm{Cd}_{5} \mathrm{Zn}_{2} \mathrm{MT}=\mathrm{Cd}$ and $\mathrm{Zn}$ bound to metallothionein; $\mathrm{CdRE}=\mathrm{Cadmium}$ response element; $\mathrm{CO}=$ Carbon monoxide; $\mathrm{COX}=$ Cytochrome $\mathrm{C}$ oxidase; GSH = Glutathione; $\mathrm{MRE}=$ Metal response element; NHE3 = Sodium hydrogen exchanger isoform 3; Nrf2= Nuclear factor erythroid 2-related factor 2; ROS = Reactive oxygen species; SGLUT = Sodium glucose co-transporter; $\mathrm{StRE}=$ Stress response element.

\section{Conclusions}

The results reviewed herein point to more widespread $\mathrm{Cd}$ exposure and a wider range of diversity of adverse effects than previously estimated. However, studies relying on the TDS, dietary recalls, and food consumption questionnaires, have failed to demonstrate such adverse health effects of $\mathrm{Cd}$ exposure that have indeed been seen in numerous studies using urinary $\mathrm{Cd}$ concentration as a quantitative measure of long-term exposure. A greater mortality risk seen in those with signs of kidney impairment, compared to those showing no such signs, suggests that kidney injury could be an early warning of complications, sub-clinical or clinical morbidity. Chronic, high-dose $\mathrm{Cd}$ exposure is 
linked to cancer death in Japanese women, and increased risk of death from ischemic heart disease, diabetes, and renal disease in both Japanese men and women, who had shown signs of extensive kidney damage and malfunction (glycosuria and proteinuria) 26 years before death (Maruzeni et al. 2014). Chronic, low-level Cd exposure in Sweden has been linked to an increased risk of heart failure (Borne et al. 2015), while chronic, low-level Cd exposure in the U.S. been linked to death from CVD, heart disease, and coronary heart disease (Tellez-Plaza et al. 2012) along with increased death from all causes (Hyder et al. 2013; Patel et al. 2013), cancer (Adams et al. 2012; Lin et al. 2014), and Alzheimer's disease (Min and Min 2016).

Results reviewed point also to the role of $\mathrm{Cd}$ exposure in the pathogenesis of hypertension and diabetes, independent of obesity. Increased risk of hypertension by $\mathrm{Cd}$ exposure has been reported for the Korean population (Lee and Kim 2012; Lee et al. 2016), Chinese population in an area with Cd contamination (Chen et al. 2015) and the U.S. population (Scinicariello et al. 2011; Franceschini et al. 2016). The U.S. population studies show that blood $\mathrm{Cd}$ level as low as $0.4 \mu \mathrm{g} / \mathrm{L}$ is associated with an increased risk of hypertension in Caucasian women (OR 1.54, 95\% CI 1.08-2.19) and in Mexican-American women (OR 2.38, 95\% CI 1.28-4.40) and that the prevalence of hypertension in Black, Caucasian and Mexican-American women (men) in the U.S. NHANES 1999-2006 was 40.7 (30.1), 32.2 (36.2) and 19.4 (16.7) \%, respectively. Increased diabetic risk by $\mathrm{Cd}$ exposure has been reported for the Korean population (Son et al. 2015), Chinese population (Nie et al. 2016) and the U.S. population (Schwartz et al. 2003; Wallia et al. 2014). In the Chinese study, a synergistic effect of $\mathrm{Cd}$ exposure and obesity on diabetic risk has also been noted (Nie et al. 2016). Diabetes and hypertension are associated with an increased risk of albuminuria, stage 3 or stage 4 CKD among NHANES 1999-2004 participants, aged between 20 and $\geq 70$ yrs, with a stronger association in younger ages (Islam et al. 2009). Thus, diabetes and hypertension are known contributing factors to ESKD. Taken together these findings imply that $\mathrm{Cd}$ exposure levels, experienced by the current U.S. population have reached the levels that adversely affect kidney health in a significant proportion of its population, thereby arguing strongly for public measures to reduce the current levels of $\mathrm{Cd}$ in human foodstuffs. Mitigation of Cd toxicity outcomes are equally necessary, given that therapeutically effective chelating agents to reduce kidney $\mathrm{Cd}$ burden is currently lacking. High rates of soil-to-plant transfer of Cd coupled with continuing mobilization of small amounts of the metal from non-bioavailable geologic matrices into biologically accessible situations predicts that human exposure to dietary $\mathrm{Cd}$ will continue to rise as will ESKD, requiring dialysis and a kidney transplant; a huge blow in health care cost and significant societal burden.

\section{Acknowledgments}

We thank the Japan Society for Promotion of Science (JSPS) for granting S. Satarug (ID, L-14568) a research professorship under the JSPS Long-term Research Invitation Program. We dedicate this work to late Professor Michael R. Moore, the Director of the National Research Centre for Environmental Toxicology (1996-2009), who was instrumental in establishment of research on health effects of heavy metals.

\section{Conflict of Interest}

The authors declare no conflict of interest.

\section{References}

Abouhamed, M., Gburek, J., Liu, W., Torchalski, B., Wilhelm, A., Wolff, N.A., Christensen, E.I., Thevenod, F. \& Smith, C.P. (2006) Divalent metal transporter 1 in the kidney proximal tubule is expressed in late endosomes/lysosomal membranes: implications for renal handling of protein-metal complexes. Am. J. Physiol. Renal Physiol., 290, F1525-F1533.

Abouhamed, M., Wolff, N.A., Lee, W.K., Smith, C.P. \& Thevenod, F. (2007) Knockdown of endosomal/lysosomal divalent metal transporter 1 by RNA interference prevents cadmium-metallothionein-1 cytotoxicity in renal proximal tubule cells. Am. J. Physiol. Renal Physiol., 293, F705-F712.

Adachi, T., Ishikawa, K., Hida, W., Matsumoto, H., Masuda, T., Date, F., Ogawa, K., Takeda, K., Furuyama, K., Zhang, Y., Kitamuro, T., Ogawa, H., Maruyama, Y. \& Shibahara, S. (2004) Hypoxemia and blunted hypoxic ventilatory responses in mice lacking heme oxygenase-2. Biochem. Biophys. Res. Commun., 320, 514-522.

Adams, S.V., Passarelli, M.N. \& Newcomb, P.A. (2012) Cadmium exposure and cancer mortality in the Third National Health and Nutrition Examination Survey cohort. Occup. Environ. Med., 69, 153-156.

Agency for Toxic Substances and Disease Registry (ATSDR) (2012) Toxicological profile for cadmium. Department of Health and Humans Services, Public Health Service, Centers for Disease Control, Atlanta, GA, USA.

Aoshima, K. (1987) Epidemiology of renal tubular dysfunction in the inhabitants of a cadmium-polluted area in the Jinzu River basin in Toyama Prefecture. Tohoku J. Exp. Med., 152, 151-172.

Arnich, N., Sirot, V., Riviere, G., Jean, J., Noel, L., Guerin, T. \& Leblanc, J.C. (2012) Dietary exposure to trace elements and health risk assessment in the 2nd French Total Diet Study. Food Chem. Toxicol., 50, 2432-2449.

Awata, H., Linder, S., Mitchell, L.E. \& Delclos, G.L. (2016) Association of dietary intake and biomarker levels of arsenic, cadmium, lead, and mercury among Asian populations in the U.S.: NHANES 2011-2012. Environ. Health Perspect., doi: 10.1289/EHP28. [Epub ahead of print].

Baker, J.R., Edwards, R.J., Lasker, J.M., Moore, M.R. \& Satarug, S. (2005) Renal and hepatic accumulation of cadmium and lead in the expression of CYP4F2 and CYP2E1. Toxicol. Lett., 159, 182-191.

Baker, J.R., Satarug, S., Edwards, R.J., Moore, M.R., Williams, D.J. \& Reilly, P.E. (2003) Potential for early involvement of CYP isoforms in aspects of human cadmium toxicity. Toxicol. Lett., 137, 85-93.

Baker, J.R., Satarug, S., Urbenjapol, S., Edwards, R.J., Williams, D.J., Moore, M.R. \& Reilly, P.E. (2002) Associations between human liver and kidney cadmium content and immunochemically detected CYP4A11 apoprotein. Biochem. Pharmacol., 63, 693-696.

Banerjee, P., Basu, A., Wegiel, B., Otterbein, L.E., Mizumura, K., Gasser, M., Waaga-Gasser, A.M., Choi, A.M. \& Pal, S. (2012) 
Heme oxygenase-1 promotes survival of renal cancer cells through modulation of apoptosis- and autophagy-regulating molecules. J. Biol. Chem., 287, 32113-32123.

Barregard, L., Bergström, G. \& Fagerberg, B. (2013) Cadmium exposure in relation to insulin production, insulin sensitivity and type 2 diabetes: a cross-sectional and prospective study in women. Environ. Res., 121, 104-109.

Barregard, L., Bergstrom, G. \& Fagerberg, B. (2014) Cadmium, type 2 diabetes, and kidney damage in a cohort of middle-aged women. Environ. Res., 135, 311-316.

Barregard, L., Fabricius-Lagging, E., Lundh, T., Molne, J., Wallin, M., Olausson, M., Modigh, C. \& Sallsten, G. (2010) Cadmium, mercury, and lead in kidney cortex of living kidney donors: Impact of different exposure sources. Environ. Res., $110,47-54$

Boonprasert, K., Satarug, S., Morais, C., Gobe, G.C., Johnson, D.W., Na-Bangchang, K. \& Vesey, D.A. (2016) The stress response of human proximal tubule cells to cadmium involves up-regulation of haemoxygenase 1 and metallothionein but not cytochrome P450 enzymes. Toxicol. Lett., 249, 5-14.

Borne, Y., Barregard, L., Persson, M., Hedblad, B., Fagerberg, B. \& Engstrom, G. (2015) Cadmium exposure and incidence of heart failure and atrial fibrillation: a population-based prospective cohort study. BMJ Open., 5, e007366.

Borne, Y., Fagerberg, B., Persson, M., Sallsten, G., Forsgard, N., Hedblad, B., Barregard, L. \& Engstrom, G. (2014) Cadmium exposure and incidence of diabetes mellitus-results from the Malmo Diet and Cancer study. PLoS One, 9, e112277.

Bridges, C.C. \& Zalups, R.K. (2005) Molecular and ionic mimicry and the transport of toxic metals. Toxicol. Appl. Pharmacol., 204, 274-308.

Buser, M.C., Ingber, S.Z., Raines, N., Fowler, D.A. \& Scinicariello, F. (2016) Urinary and blood cadmium and lead and kidney function: NHANES 2007-2012. Int. J. Hyg. Environ. Health, 219, 261-267.

Callan, A., Hinwood, A. \& Devine, A. (2014) Metals in commonly eaten groceries in Western Australia: a market basket survey and dietary assessment. Food Addit. Contam. A Chem. Anal. Control Expo. Risk Assess., 31, 1968-1981.

Callan, A.C., Devine, A., Qi, L., Ng, J.C. \& Hinwood, A.L. (2015) Investigation of the relationship between low environmental exposure to metals and bone mineral density, bone resorption and renal function. Int. J. Hyg. Environ. Health, 218, 444-451.

Canonne-Hergaux, F. \& Gros, P. (2002) Expression of the iron transporter DMT1 in kidney from normal and anemic mk mice. Kidney Int., 62, 147-156.

Chaumont, A., Nickmilder, M., Dumont, X., Lundh, T., Skerfving, S. \& Bernard, A. (2012) Associations between proteins and heavy metals in urine at low environmental exposures: evidence of reverse causality. Toxicol. Lett., 210, 345- 352.

Chen, X., Wang, Z., Zhu, G., Liang, Y. \& Jin, T. (2015) Benchmark dose estimation of cadmium reference level for hypertension in a Chinese population. Environ. Toxicol. Pharmacol., 39, 208-212.

Cheriyath, P., Gorrepati, V.S., Peters, I., Nookala, V., Murphy, M.E., Srouji, N. \& Fischman, D. (2010) High total bilirubin as a protective factor for diabetes mellitus: an analysis of NHANES data from 1999-2006. J. Clin. Med. Res., 2, 201-206.

Cheung, B.M.Y., Ong, K.L. \& Wong, L.Y.F. (2009) Elevated serum alkaline phosphatase and peripheral arterial disease in the United States National Health and Nutrition Examination Survey 1999-2004. Int. J. Cardiol., 135, 156-161.

Choi, S.W., Yeung, V.T.F., Collins, A.R. \& Benzie, I.F.F. (2015) Redox-linked effects of green tea on DNA damage and repair, and influence of microsatellite polymorphism in HMOX-1: results of a human intervention trial. Mutagenesis, 30, 129-137.

Colacino, J.A., Arthur, A.E., Ferguson, K.K. \& Rozek, L.S. (2014)
Dietary antioxidant and anti-inflammatory intake modifies the effect of cadmium exposure on markers of systemic inflammation and oxidative stress. Environ. Res., 131, 6-12.

Copes, R., Clark, N.A., Rideout, K., Palaty, J. \& Teschke, K. (2008) Uptake of cadmium from Pacific oysters (Crassostrea gigas) in British Columbia oyster growers. Environ. Res., 107, 160-169.

Crews, D.C., Plantinga, L.C., Miller, E.R., Saran, R., Hedgeman, E., Saydah, S.H., Williams, D.E. \& Powe, N.R. (2010) Prevalence of chronic kidney disease in persons with undiagnosed or prehypertension in the United States. Hypertension, 55, 1102-1109.

Crowley, S.D. \& Coffman, T.M. (2014) The inextricable role of the kidney in hypertension. J. Clin. Invest., 124, 2341-2347.

Cusi, K. (2012) Role of obesity and lipotoxicity in the development of nonalcoholic steatohepatitis: pathophysiology and clinical implications. Gastroenterol., 142, 711-725.

Davies, K.J.A. (2016) Adaptive homeostasis. Mol. Aspects Med., 49, $1-7$.

Dunn, L.L., Midwinter, R.G., Ni, J., Hamid, H.A., Christopher, R., Parish, C.R. \& Stocker, R. (2014) New insights into intracellular locations and functions of heme oxygenase-1. Antioxid. Redox Signal., 20, 1723-1742.

Durante, W. (2010) Targeting heme oxygenase-1 in vascular disease. Curr. Drug Targets, 11, 1504-1516.

Dziubanek, G., Piekut, A., Rusin, M., Baranowska, R. \& Hajok, I. (2015) Contamination of food crops grown on soils with elevated heavy metals content. Ecotoxicol. Environ. Saf., 118, 183-189.

Ellis, J.K., Athersuch, T.J., Thomas, L.D., Teichert, F., PérezTrujillo, M., Svendsen, C., Spurgeon, D.J., Singh, R., Järup, L., Bundy, J.G. \& Keun, H.C. (2012) Metabolic profiling detects early effects of environmental and lifestyle exposure to cadmium in a human population. BMC Med., 10, 61.

Engelmann, J., Manuwald, U., Rubach, C., Kugler, J., Birkenfeld, A.L., Hanefeld, M. \& Rothe, U. (2016) Determinants of mortality in patients with type 2 diabetes: a review. Rev. Endocr. Metab. Disord., 17, 129-137.

Fan, F., Muroya, Y. \& Roman, R.J. (2015) Cytochrome P450 eicosanoids in hypertension and renal disease. Curr. Opin. Nephrol. Hypertens., 24, 37-46.

Feng, W., Cui, X., Liu, B., Liu, C., Xiao, Y., Lu, W., Guo, H., He, M., Zhang, X., Yuan, J., Chen, W. \& Wu, T. (2015) Association of urinary metal profiles with altered glucose levels and diabetes risk: a population-based study in China. PLoS One., 10, $\mathrm{e} 0123742$.

Ferguson, C.J., Wareing, M., Ward, D.T., Green, R., Smith, C.P. \& Riccardi, D. (2001) Cellular localization of divalent metal transporter DMT-1 in rat kidney. Am. J. Physiol. Renal Physiol., 280, F803-F814.

Ferraro, P.M., Costanzi, S., Naticchia, A., Sturniolo, A. \& Gambaro, G. (2010) Low level exposure to cadmium increases the risk of chronic kidney disease: analysis of the NHANES 1999-2006. BMC Public Health, 10, 304.

Franceschini, N., Fry, R.C., Balakrishnan, P., Navas-Acien, A., Oliver-Williams, C., Howard, A.G., Cole, S.A., Haack, K., Lange, E.M., Howard, B.V., Best, L.G., Francesconi, K.A., Goessler, W., Umans, J.G. \& Tellez-Plaza, M. (2016) Cadmium body burden and increased blood pressure in middle-aged American Indians: the Strong Heart Study. $J$. Hum. Hypertens., doi: 10.1038/jhh.2016.67. [Epub ahead of print].

Fransson, M.N., Barregard, L., Sallsten, G., Akerstrom, M. \& Johanson, G. (2014) Physiologically-based toxicokinetic model for cadmium using Markov-Chain Monte Carlo analysis of concentrations in blood, urine, and kidney cortex from living kidney donors. Toxiol. Sci., 141, 365-376.

Fujita, Y., el Belbasi, H.I., Min, K.S., Onosaka, S., Okada, Y., Matsumoto, Y., Mutoh, N. \& Tanaka, K. (1993) Fate of 
cadmium bound to phytochelatin in rats. Res. Commun. Chem. Pathol. Pharmacol., 82, 357-365.

Fujiwara, Y., Lee, J.Y., Tokumoto, M. \& Satoh, M. (2012) Cadmium renal toxicity via apoptotic pathways. Biol. Pharm. Bull., 35, 1892-1897.

Garner, R. \& Levallois, P. (2016) Cadmium levels and sources of exposure among Canadian adults. Health Rep., 27, 10-18.

Garrett, S.H., Somji, S., Sens, M.A., Zhang, K. \& Sens, D.A. (2011) Microarray analysis of gene expression patterns in human proximal tubule cells over a short and long time course of cadmium exposure. J. Toxicol. Environ. Health A, 74, 24-42.

Girijashanker, K., He, L., Soleimani, M., Reed, J.M., Li, H., Liu, Z., Wang, B., Dalton, T.P. \& Nebert, D.W. (2008) Slc39a14 gene encodes ZIP14, a metal/bicarbonate symporter: similarities to the ZIP8 transporter. Mol. Pharmacol., 73, 1413-1423.

Gobe, G. \& Crane, D. (2010) Mitochondria, reactive oxygen species and cadmium toxicity in the kidney. Toxicol. Lett., 198, 49-55.

Guan, S., Palermo, T. \& Meliker, J. (2015) Seafood intake and blood cadmium in a cohort of adult avid seafood consumers. Int. J. Hyg. Environ. Health, 218, 147-152.

Gunshin, H., Mackenzie, B., Berger, U.V., Gunshin, Y., Romero, M.F., Boron, W.F., Nussberger, S., Gollan, J.L. \& Hediger, M.A. (1997) Cloning and characterization of a mammalian proton-coupled metal-ion transporter. Nature, 388, 482-488.

Han, K.C., Wong, W.C. \& Benzie, I.F.F. (2011) Genoprotective effects of green tea (Camellia sinensis) in human subjects: results of a controlled supplementation trial. Br. J. Nutri., 105, 171-179.

Havasi, A. \& Dong, Z. (2016) Autophagy and tubular cell death in the kidney. Semin. Nephrol., 36, 174-188.

He, L., Wang, B., Hay, E.B. \& Nebert, D.W. (2009) Discovery of ZIP transporters that participate in cadmium damage to testis and kidney. Toxicol. Appl. Pharmacol., 238, 250-257.

Himeno, S., Yanagiya, T., Enomoto, S., Kondo, Y. \& Imura, N. (2002) Cellular cadmium uptake mediated by the transport system for manganese. Tohoku J. Exp. Med., 196, 43-50.

Hinwood, A.L., Callan, A.C., Ramalingam, M., Boyce, M., Heyworth, J., McCafferty, P. \& Odland, J.O. (2013) Cadmium, lead and mercury exposure in nonsmoking pregnant women. Environ. Res., 126, 118-124.

Honda, R., Swaddiwudhipong, W., Nishijo, M., Mahasakpan, P., Teeyakasem, W., Ruangyuttikarn, W., Satarug, S., Padungtod, C. \& Nakagawa, H. (2010) Cadmium induced renal dysfunction among residents of rice farming area downstream from a zinc-mineralized belt in Thailand. Toxicol. Lett., 198, 26-32.

Horiguchi, H., Aoshima, K., Oguma, E., Sasaki, S., Miyamoto, K., Hosoi, Y., Katoh, T. \& Kayama, F. (2010) Latest status of cadmium accumulation and its effects on kidneys, bone, and erythropoiesis in inhabitants of the formerly cadmium-polluted Jinzu River Basin in Toyama, Japan, after restoration of rice paddies. Int. Arch. Occup. Environ. Health, 83, 953-970.

Horsfall, L.J., Nazareth, I. \& Petersen, I. (2012) Cardiovascular events as a function of serum bilirubin levels in a large, statintreated cohort. Circulation, 126, 2556-2564.

Hwangbo, Y., Weaver, V.M., Tellez-Plaza, M., Guallar, E., Lee, B.K. \& Navas-Acien, A. (2011) Blood cadmium and estimated glomerular filtration rate in Korean adults. Environ. Health Perspect., 119, 1800-1805.

Hyder, O., Chung, M., Cosgrove, D., Herman, J.M., Li, Z., Firoozmand, A., Gurakar, A., Koteish, A. \& Pawlik, T.M. (2013) Cadmium exposure and liver disease among US adults. J. Gastrointest. Surg., 17, 1265-1273.

Igarashi, K. \& Watanabe-Matsui, M. (2014) Wearing red for signaling: The Heme-Bach axis in heme metabolism, oxidative stress response and iron immunology. Tohoku J. Exp. Med., 232, 229-253.

Islam, T.M., Fox, C.S., Mann, D. \& Muntner, P. (2009) Age- related associations of hypertension and diabetes mellitus with chronic kidney disease. BMC Nephrol., 10, 17.

Itoh, K., Ye, P., Matsumiya, T., Tanji, K. \& Ozaki, T. (2015) Emerging functional cross-talk between the Keap1-Nrf2 system and mitochondria. J. Clin. Biochem. Nutr., 56, 91-97.

Jain, R.B. (2013) Effect of pregnancy on the levels of blood cadmium, lead, and mercury for females aged 17-39 years old: data from National Health and Nutrition Examination Survey 2003-2010. J. Toxicol. Environ. Health A, 76, 58-69.

Johnson, A.L., Edson, K.Z., Totah, R.A. \& Rettie, A.E. (2015) Cytochrome P450 $\omega$-hydroxylases in inflammation and cancer. Adv. Pharmacol., 74, 223-262.

Kaler, P. \& Prasad, R. (2007) Molecular cloning and functional characterization of novel zinc transporter rZip10 (Slc39a10) involved in zinc uptake across rat renal brush-border membrane. Am. J. Physiol. Renal Physiol., 292, F217-F229.

Khan, A.A. \& Quigley, J.G. (2011) Control of intracellular heme levels: heme transporters and heme oxygenases. Biochim. Biophys. Acta, 1813, 668-682.

Kim, E.C., Cho, E. \& Jee, D. (2014) Association between blood cadmium level and age-related macular degeneration in a representative Korean population. Invest. Ophthalmol. Vis. Sci., 55, 5702-5710.

Kim, N.H., Hyun, Y.Y., Lee, K.B., Chang, Y., Ryu, S., Oh, K.H. \& Ahn, C. (2015) Environmental heavy metal exposure and chronic kidney disease in the general population. J. Korean Med. Sci., 30, 272-277.

Kim, M.H., Zhao, D., Cho, J. \& Guallar, E. (2016) Cadmium exposure and age-related macular degeneration. J. Expo. Sci. Environ. Epidemiol., 26, 214-218.

Klassen, R.B., Crenshaw, K., Kozyraki, R., Verroust, P.J., Tio, L., Atrian, S., Allen, P.L. \& Hammond, T.G. (2004) Megalin mediates renal uptake of heavy metal metallothionein complexes. Am. J. Physiol. Renal Physiol., 287, F393-F403.

Kovacs, G., Danko, T., Bergeron, M.J., Balazs, B., Suzuki, Y., Zsembery, A. \& Hediger, M.A. (2011) Heavy metal cations permeate the TRPV6 epithelial cation channel. Cell Calcium., 49, 43-55.

Krone, C.A., Wyse, E.J. \& Ely, J.T. (2001) Cadmium in zinccontaining mineral supplements. Int. J. Food Sci. Nutr., 52, 379-382.

Kudo, K., Konta, T., Mashima, Y., Ichikawa, K., Takasaki, S., Ikeda, A., Hoshikawa, M., Suzuki, K., Shibata, Y., Watanabe, T., Kato, T., Kawata, S. \& Kubota, I. (2011) The association between renal tubular damage and rapid renal deterioration in the Japanese population: the Takahata study. Clin. Exp. Nephrol., 15, 235-241.

Kunutsor, S.K., Bakker, S.J.L., Gansevoort, R.T., Chowdhury, R. \& Dullaart, R.P.F. (2015) Circulating total bilirubin and risk of incident cardiovascular disease in the general population. Arterioscler. Thromb. Vasc. Biol., 35, 716-724.

Laffer, C.L., Laniado-Schwartzman, M., Wang, M.H., Nasjletti, A. \& Elijovich, F. (2003a) Differential regulation of natriuresis by 20 -hydroxyeicosatetraenoic acid in human salt-sensitive versus salt-resistant hypertension. Circulation, 107, 574-578.

Laffer, C.L., Laniado-Schwartzman, M., Wang, M.H., Nasjletti, A. \& Elijovich, F. (2003b) 20-HETE and furosemide-induced natriuresis in salt-sensitive essential hypertension. Hypertension, 41, 703-708.

Lasker, J.M., Chen, W.B., Wolf, I., Bloswick, B.P., Wilson, P.D. \& Powell, P.K. (2000) Formation of 20-hydroxyeicosatetraenoic acid, a vasoactive and natriuretic eicosanoid, in human kidney. Role of CYP4F2 and CYP4A11. J. Biol. Chem., 275, 41184126.

Lee, B.K., Ahn, J., Kim, N.S., Lee, C.B., Park, J. \& Kim, Y. (2016) Association of blood pressure with exposure to lead and cadmium: analysis of data from the 2008-2013 Korean National Health and Nutrition Examination Survey. Biol. Trace Elem. Res., 174, 40-51. 
Lee, B.K. \& Kim, Y. (2012) Association of blood cadmium with hypertension in the Korean general population: analysis of the 2008-2010 Korean National Health and Nutrition Examination Survey data. Am. J. Ind. Med., 55, 1060-1067.

Lee, D.H., Lim, J.S., Song, K., Boo, Y. \& Jacobs, D.R. Jr. (2006) Graded associations of blood lead and urinary cadmium concentrations with oxidative-stress-related markers in the U.S. population: results from the third National Health and Nutrition Examination Survey. Environ. Health Perspect., 114, 350-354.

Levitt, D.G. \& Levitt, M.D. (2015) Carbon monoxide: a critical quantitative analysis and review of the extent and limitations of its second messenger function. Clin. Pharmacol., 7, 37-56.

Li, Y., Oo, Z.Y., Chang, S.Y., Huang, P., Eng, K.G., Zeng, J.L., Kaestli, A.J., Gopalan, B., Kandasamy, K., Tasnim, F. \& Zink, D. (2013) An in vitro method for the prediction of renal proximal tubular toxicity in humans. Toxicol. Res., 2, 352-365.

Lin, J.P., Vitek, L. \& Schwertner, H.A. (2010) Serum bilirubin and genes controlling bilirubin concentrations as biomarkers for cardiovascular disease. Clin. Chem., 56, 1535-1543.

Lin, Y.S., Caffrey, J.L., Lin, J.W., Bayliss, D., Faramawi, M.F., Bateson, T.F. \& Sonawane, B. (2013) Increased risk of cancer mortality associated with cadmium exposures in older Americans with low zinc intake. J. Toxicol. Environ. Health A, 76, $1-15$.

Lin, Y.S., Ho, W.C., Caffrey, J.L. \& Sonawane, B. (2014) Low serum zinc is associated with elevated risk of cadmium nephrotoxicity. Environ. Res., 134, 33-38.

Lin, Y.S., Rathod, D., Ho, W.C. \& Caffrey, J.L. (2009) Cadmium exposure is associated with elevated blood C-reactive protein and fibrinogen in the U.S. population: the third national health and nutrition examination survey (NHANES III, 1988-1994). Ann. Epidemiol., 19, 592-596.

Lumeng, C.N. \& Saltiel, A.R. (2011) Inflammatory links between obesity and metabolic disease. J. Clin. Invest., 121, 21112117.

Madeddu, R., Solinas, G., Forte, G., Bocca, B., Asara, Y., Tolu, P., Delogu, L.G., Muresu, E., Montella, A. \& Castiglia, P. (2011) Diet and nutrients are contributing factors that influence blood cadmium levels. Nutr. Res., 31, 691-697.

Mashima, Y., Konta, T., Kudo, K., Takasaki, S., Ichikawa, K., Suzuki, K., Shibata, Y., Watanabe, T., Kato, T., Kawata, S. \& Kubota, I. (2011) Increases in urinary albumin and beta2microglobulin are independently associated with blood pressure in the Japanese general population: the Takahata Study. Hypertens. Res., 34, 831-835.

Maruzeni, S., Nishijo, M., Nakamura, K., Morikawa, Y., Sakurai, M., Nakashima, M., Kido, T., Okamoto, R., Nogawa, K., Suwazono, Y. \& Nakagawa, H. (2014) Mortality and causes of deaths of inhabitants with renal dysfunction induced by cadmium exposure of the polluted Jinzu River basin, Toyama, Japan; a 26-year follow-up. Environ. Health, 13, 18.

Meltzer, H.M., Brantsaeter, A.L., Borch-Iohnsen, B., Ellingsen, D.G., Alexander, J., Thomassen, Y., Stigum, H. \& Ydersbond, T.A. (2010) Low iron stores are related to higher blood concentrations of manganese, cobalt and cadmium in nonsmoking, Norwegian women in the HUNT 2 study. Environ. Res., 110, 497-504.

Min, J.Y. \& Min, K.B. (2016) Blood cadmium levels and Alzheimer's disease mortality risk in older US adults. Environ. Health, 15, 69.

Minh, N.G., Hough, R.L., Thuy, L.T., Nyberg, Y., Mai, L.B., Vinh, N.C., Khai, N.M. \& Oborn, I. (2012) Assessing dietary exposure to cadmium in a metal recycling community in Vietnam: age and gender aspects. Sci. Total Environ., 416,164-171.

Mortensen, M.E., Wong, L.Y. \& Osterloh, J.D. (2011) Smoking status and urine cadmium above levels associated with subclinical renal effects in U.S. adults without chronic kidney disease. Int. J. Hyg. Environ. Health, 214, 305-310.
Nakhoul, N. \& Batuman, V. (2011) Role of proximal tubules in the pathogenesis of kidney disease. Contrib. Nephrol., 169, 37-50.

Nair, A.R., Lee, W.K., Smeets, K., Swennen, Q., Sanchez, A., Thevenod, F. \& Cuypers, A. (2015) Glutathione and mitochondria determine acute defense responses and adaptive processes in cadmium-induced oxidative stress and toxicity of the kidney. Arch. Toxicol., 89, 2273-2289.

Nebert, D.W., Galvez-Peralta, M., Hay, E.B., Li, H., Johansson, E., Yin, C., Wang, B., He, L. \& Soleimani, M. (2012) ZIP14 and ZIP8 zinc/bicarbonate symporters in Xenopus oocytes: characterization of metal uptake and inhibition. Metallomics, 4, 1218-1225.

Nie, X., Wang, N., Chen, Y., Chen, C., Han, B., Zhu, C., Chen, Y., Xia, F., Cang, Z., Lu, M., Meng, Y., Jiang, B., Jensen, D.M. \& Lu, Y. (2016) Blood cadmium in Chinese adults and its relationships with diabetes and obesity. Environ. Sci. Pollut. Res. Int., 23, 18714-18723.

Nielsen, R., Christensen, E.I. \& Birn, H. (2016) Megalin and cubilin in proximal tubule protein reabsorption: from experimental models to human disease. Kidney Int., 89, 58-67.

Nishijo, M., Satarug, S., Honda, R., Tsuritani, I. \& Aoshima, K. (2004) The gender differences in health effects of environmental cadmium exposure and potential mechanisms. Mol. Cell. Biochem., 255, 87-92.

Ohashi, N., Isobe, S., Ishigaki, S. \& Yasuda, H. (2016) Circadian rhythm of blood pressure and the renin-angiotensin system in the kidney. Hypertens. Res., doi: 10.1038/hr.2016.166. [Epub ahead of print].

Ohta, K., Yachie, A., Fujimoto, K., Kaneda, H., Wada, T., Toma, T., Seno, A., Kasahara, Y., Yokoyama, H., Seki, H. \& Koizumi, S. (2000) Tubular injury as a cardinal pathologic feature in human heme oxygenase-1 deficiency. Am. J. Kidney Dis., 35, 863-870.

Olsen, L., Lind, P.M. \& Lind, L. (2012) Gender differences for associations between circulating levels of metals and coronary risk in the elderly. Int. J. Hyg. Environ. Health, 215, 411-417.

Osawa, T., Kobayashi, E., Okubo, Y., Suwazono, Y., Kido, T. \& Nogawa, K. (2001) A retrospective study on the relation between renal dysfunction and cadmium concentration in rice in individual hamlets in the Jinzu River Basin, Toyama prefecture, Japan. Environ. Res., 86, 51-59.

Padilla, M.A., Elobeid, M., Ruden, D.M. \& Allison, D.B. (2010) An examination of the association of selected toxic metals with total and central obesity indices: NHANES 99-02. Int. J. Environ. Res. Public Health, 7, 3332-3347.

Patel, C.J., Manrai, A.K., Corona, E. \& Kohane, I.S. (2016) Systematic correlation of environmental exposure and physiological and self-reported behaviour factors with leukocyte telomere length. Int. J. Epidemiol., doi: 10.1093/ije/dyw043. [Epub ahead of print].

Patel, C.J., Rehkopf, D.H., Leppert, J.T., Bortz, W.M., Cullen, M.R., Chertow, G.M. \& Ioannidis, J.P. (2013) Systematic evaluation of environmental and behavioural factors associated with all-cause mortality in the United States national health and nutrition examination survey. Int. J. Epidemiol., 42, 1795-1810.

Pizzol, M., Smart, J.C.R. \& Thomsen, M. (2014) External costs of cadmium emissions to soil: a drawback of phosphorus fertilizers. J. Clean. Prod., 84, 475-483.

Pollack, A.Z., Mumford, S.L., Mendola, P., Perkins, N.J., Rotman, Y., Wactawski-Wende, J. \& Schisterman, E.F. (2015) Kidney biomarkers associated with blood lead, mercury, and cadmium in premenopausal women: a prospective cohort study. $J$. Toxicol. Environ. Health A, 78, 119-131.

Prozialeck, W.C. \& Edwards, J.R. (2012) Mechanisms of cadmium-induced proximal tubule injury: new insights with implications for biomonitoring and therapeutic interventions. J. Pharmacol. Exp. Ther., 343, 2-12.

Rahman, M.A., Rahman, M.M., Reichman, S.M., Lim, R.P. \& 
Naidu, R. (2014) Heavy metals in Australian grown and imported rice and vegetables on sale in Australia: health hazard. Ecotoxicol. Environ. Saf., 100, 53-60.

Reed, J.W. (2016) Impact of sodium-glucose cotransporter 2 inhibitors on blood pressure. Vasc. Health Risk Manag., 12, 393-405.

Riederer, A.M., Belova, A., George, B.J. \& Anastas, P.T. (2013) Urinary cadmium in the 1999-2008 U.S. National Health and Nutrition Examination Survey (NHANES). Environ. Sci Technol., 47, 1137-1147.

Sand, S. \& Becker, W. (2012) Assessment of dietary cadmium exposure in Sweden and population health concern including scenario analysis. Food Chem. Toxicol., 50, 536-544.

Sasso, A.F., Schlosser, P.M., Kedderis, G.L., Genter, M.B., Snawder, J.E., Li, Z., Rieth, S. \& Lipscomb, J.C. (2013) Application of an updated physiologically based pharmacokinetic model for chloroform to evaluate CYP2E1-mediated renal toxicity in rats and mice. Toxicol. Sci., 131, 360-374.

Satarug, S., Baker, J.R., Reilly, P.E., Moore, M.R. \& Williams, D.J. (2001) Changes in zinc and copper homeostasis in human livers and kidneys associated with exposure to environmental cadmium. Hum. Exp. Toxicol., 20, 205-213.

Satarug, S., Baker, J.R., Reilly, P.E., Moore, M.R. \& Williams, D.J. (2002) Cadmium levels in the lung, liver, kidney cortex, and urine samples from Australians without occupational exposure to metals. Arch. Environ. Health, 57, 69-77.

Satarug, S., Baker, J.R., Urbenjapol, S., Haswell-Elkins, M., Reilly, P.E., Williams, D.J. \& Moore, M.R. (2003) A global perspective on cadmium pollution and toxicity in non-occupationally exposed population. Toxicol. Lett., 137, 65-83.

Satarug, S., Garrett, S.H., Sens, M.A. \& Sens, D.A. (2010) Cadmium, environmental exposure, and health outcomes. Environ. Health Perspect., 118, 182-190.

Satarug, S., Haswell-Elkins, M.R. \& Moore, M.R. (2000) Safe levels of cadmium intake to prevent renal toxicity in human subjects. Br. J. Nutr., 84, 791-802.

Satarug, S. \& Moore, M.R. (2012) Emerging roles of cadmium and heme oxygenase in type-2 diabetes and cancer susceptibility. Tohoku J. Exp. Med., 228, 267-288.

Satarug, S., Nishijo, M., Lasker, J.M., Edwards, R.J. \& Moore, M.R. (2006) Kidney dysfunction and hypertension: role for cadmium, p450 and heme oxygenases? Tohoku J. Exp. Med., 208, 179-202.

Satarug, S., Nishijo, M., Ujjin, P., Vanavanitkun, Y. \& Moore, M.R. (2005) Cadmium-induced nephropathy in the development of high blood pressure. Toxicol. Lett., 157, 57-68.

Satarug, S., Swaddiwudhipong, W., Ruangyuttikarn, W., Nishijo, M. \& Ruiz, P. (2013) Modeling cadmium exposures in lowand high-exposure areas in Thailand. Environ. Health Perspect., 121, 531-536.

Satarug, S., Vesey, D. \& Gobe, G. (2016) Health risk assessment of dietary cadmium intake: do current guidelines indicate how much is safe? Environ. Health Perspect., doi: 10.1289/ EHP108. [Epub ahead of print].

Schwartz, G.G., Il'yasova, D. \& Ivanova, A. (2003) Urinary cadmium, impaired fasting glucose, and diabetes in the NHANES III. Diabetes Care, 26, 468-470.

Schroeder, H.A. \& Balassa, J.J. (1963) Cadmium: uptake by vegetables from superphosphate in soil. Science, 140, 819-820.

Scinicariello, F., Abadin, H.G. \& Murray, H.E. (2011) Association of low-level blood lead and blood pressure in NHANES 19992006. Environ. Res., 111, 1249-1257.

Sena, L.A. \& Chandel, N.S. (2012) Physiological roles of mitochondrial reactive oxygen species. Mol. Cell, 48, 158-167.

Shibahara, S. (2003) The heme oxygenase dilemma in cellular homeostasis: new insights for the feedback regulation of heme catabolism. Tohoku J. Exp. Med., 200, 167-186.

Shibahara, S., Han, F., Li, B. \& Takeda, K. (2007) Hypoxia and heme oxygenases: oxygen sensing and regulation of expres- sion. Antiox. Redox Signal., 9, 2209-2225.

Small, D.M., Coombes, J.S., Bennett, N., Johnson, D.W. \& Gobe, G.C. (2012) Oxidative stress, anti-oxidant therapies and chronic kidney disease. Nephrology, 17, 311-321.

Soderland, P., Lovekar, S., Weiner, D.E., Brooks, D.R. \& Kaufman, J.S. (2010) Chronic kidney disease associated with environmental toxins and exposures. Adv. Chronic Kidney Dis., 17, 254-264.

Son, H.S., Kim, S.G., Suh, B.S., Park, D.U., Kim, D.S., Yu, S.D., Hong, Y.S., Park, J.D., Lee, B.K., Moon, J.D. \& Sakong, J. (2015) Association of cadmium with diabetes in middle-aged residents of abandoned metal mines: the first health effect surveillance for residents in abandoned metal mines. Ann. Occup. Environ. Med., 27, 20.

Subramanya, A.R. \& Ellison, D.H. (2014) Distal convoluted tubule. Clin. J. Am. Soc. Nephrol., 9, 2147-2163.

Suh, Y.J., Lee, J.E., Lee, D.H., Yi, H.G., Lee, M.H., Kim, C.S., Nah, J.W. \& Kim, S.K. (2016) Prevalence and relationships of iron deficiency anemia with blood cadmium and vitamin D levels in Korean women. J. Korean Med. Sci., 31, 25-32.

Suvagandha, D., Nishijo, M., Swaddiwudhipong, W., Honda, R., Ohse, M., Kuhara, T., Nakagawa, H. \& Ruangyuttikarn, W. (2014) A biomarker found in cadmium exposed residents of Thailand by metabolome analysis. Int. J. Environ. Res. Public Health, 11, 3661-3677.

Suwazono, Y., Kido, T., Nakagawa, H., Nishijo, M., Honda, R., Kobayashi, E., Dochi, M. \& Nogawa, K. (2009) Biological half-life of cadmium in the urine in the habitats after cessation of exposure. Biomarkers, 14, 77-81.

Tellez-Plaza, M., Navas-Acien, A., Crainiceanu, C.M., Sharrett, A.R. \& Guallar, E. (2010) Cadmium and peripheral arterial disease: gender differences in the 1999-2004 US National Health and Nutrition Examination Survey. Am. J. Epidemiol., 172, 671-681.

Tellez-Plaza, M., Navas-Acien, A., Menke, A., Crainiceanu, C.M., Pastor-Barriuso, R. \& Guallar, E. (2012) Cadmium exposure and all-cause and cardiovascular mortality in the U.S. general population. Environ. Health Perspect., 120, 1017-1022.

Thevenod, F. (2003) Nephrotoxicity and the proximal tubule. Insights from cadmium. Nephron Physiol., 93, 87-93.

Thevenod, F. \& Friedmann, J.M. (1999) Cadmium-mediated oxidative stress in kidney proximal tubule cells induces degradation of $\mathrm{Na}+/ \mathrm{K}+$-ATPase through proteasomal and endo-/ lysosomal proteolytic pathways. FASEB J., 13, 1751-1761.

Thevenod, F. \& Wolff, N.A. (2016) Iron transport in the kidney: implications for physiology and cadmium nephrotoxicity. Metallomics, 8, 17-42.

Vacchi-Suzzi, C., Eriksen, K.T., Levine, K., McElroy, J., Tjonneland, A., Raaschou-Nielsen, O., Harrington, J.M. \& Meliker, J.R. (2015) Dietary intake estimates and urinary cadmium levels in Danish postmenopausal women. PLoS One, 10, e 0138784.

Vallon, V. (2015) The mechanisms and therapeutic potential of SGLT2 inhibitors in diabetes mellitus. Annu. Rev. Med., 66, 255-270.

Vance, T.M. \& Chun, O.K. (2015) Zinc intake is associated with lower cadmium burden in U.S. adults. J. Nutr., 145, 27412748.

Vesey, D.A. (2010) Transport pathways for cadmium in the intestine and kidney proximal tubule: focus on the interaction with essential metals. Toxicol. Lett., 198, 13-19.

Wallia, A., Allen, N.B., Badon, S. \& El Muayed, M. (2014) Association between urinary cadmium levels and prediabetes in the NHANES 2005-2010 population. Int. J. Hyg. Environ. Health, 217, 854-860.

Wallin, M., Sallsten, G., Lundh, T. \& Barregard, L. (2014) Lowlevel cadmium exposure and effects on kidney function. Occup. Environ. Med., 71, 848-854.

Wang, Y., Zalups, R.K. \& Barfuss, D.W. (2010) Potential mechanisms involved in the absorptive transport of cadmium in 
isolated perfused rabbit renal proximal tubules. Toxicol. Lett., 193, 61-68.

Ward, N.C., Puddey, I.B., Hodgson, J.M., Beilin, L.J. \& Croft, K.D. (2005) Urinary 20-hydroxyeicosatetraenoic acid excretion is associated with oxidative stress in hypertensive subjects. Free Radic. Biol. Med., 38, 1032-1036.

Ward, N.C., Rivera, J., Hodgson, J., Puddey, I.B., Beilin, L.J., Falck, J.R. \& Croft, K.D. (2004) Urinary 20-hydroxyeicosatetraenoic acid is associated with endothelial dysfunction in humans. Circulation, 110, 438-443.

Wilding, J.P.H. (2014) The role of the kidneys in glucose homeostasis in type 2 diabetes: clinical implications and therapeutic significance through sodium glucose co-transporter 2 inhibitors. Metabolism, 63, 1228-1237.

Wolff, N.A., Abouhamed, M., Verroust, P.J. \& Thevenod, F. (2006) Megalin-dependent internalization of cadmium-metallothionein and cytotoxicity in cultured renal proximal tubule cells. J. Pharmacol. Exp. Ther., 318, 782-791.
Wu, C.C., Gupta, T., Garcia, V., Ding, Y. \& Schwartzman, M.L. (2014a) 20-HETE and blood pressure regulation: clinical implications. Cardiol. Rev., 22, 1-12.

Wu, E.W., Schaumberg, D.A. \& Park, S.K. (2014b) Environmental cadmium and lead exposures and age-related macular degeneration in U.S. adults: the National Health and Nutrition Examination Survey 2005 to 2008. Environ. Res., 133, 178-184.

Yagihashi, S., Inaba, W. \& Mizukami, H. (2016) Dynamic pathology of islet endocrine cells in type 2 diabetes: $\beta$-Cell growth, death, regeneration and their clinical implications. $J$. Diabetes Investig., 7, 155-165.

Zota, A.R., Needham, B.L., Blackburn, E.H., Lin, J., Park, S.K., Rehkopf, D.H. \& Epe, E.S. (2015) Associations of cadmium and lead exposure with leukocyte telomere length: findings from National Health and Nutrition Examination Survey, 1999-2002 . Am. J. Epidemiol., 181, 127-136. 